\title{
Nanoporous Cubic Silicon Carbide Photoanodes for Enhanced Solar Water Splitting
}

\author{
Jing-Xin Jian, Valdas Jokubavicius, Mikael Syväjärvi, Rositsa Yakimova, and Jianwu Sun*
}

Cite This: ACS Nano 2021, 15, 5502-5512

Read Online

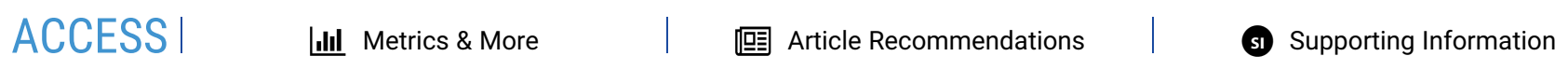

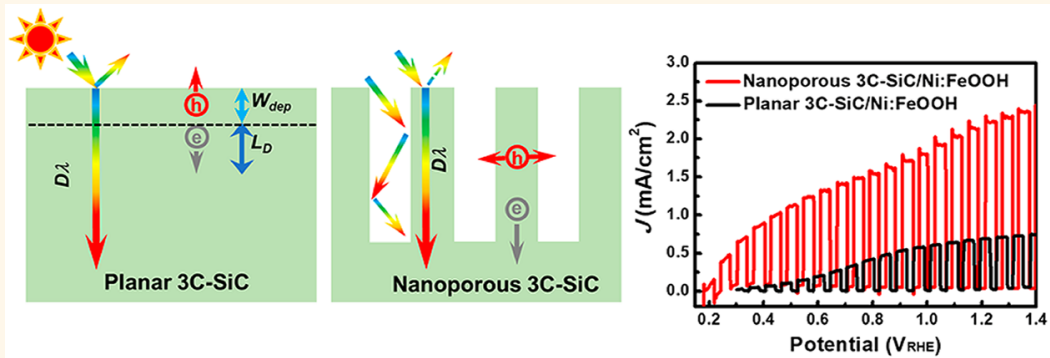

ABSTRACT: Cubic silicon carbide (3C-SiC) is a promising photoelectrode material for solar water splitting due to its relatively small band gap $(2.36 \mathrm{eV})$ and its ideal energy band positions that straddle the water redox potentials. However, despite various coupled oxygen-evolution-reaction (OER) cocatalysts, it commonly exhibits a much smaller photocurrent $\left.(<\sim 1 \mathrm{~mA} \mathrm{~cm})^{-2}\right)$ than the expected value $\left(8 \mathrm{~mA} \mathrm{~cm}^{-2}\right)$ from its band gap under AM1.5G 100 $\mathrm{mW} \mathrm{cm} \mathrm{cm}^{-2}$ illumination. Here, we show that a short carrier diffusion length with respect to the large light penetration depth in $3 \mathrm{C}-\mathrm{SiC}$ significantly limits the charge separation, thus resulting in a small photocurrent. To overcome this drawback, this work demonstrates a facile anodization method to fabricate nanoporous $3 \mathrm{C}$-SiC photoanodes coupled with $\mathrm{Ni}: \mathrm{FeOOH}$ cocatalyst that evidently improve the solar water splitting performance. The optimized nanoporous 3C-SiC shows a high photocurrent density of $2.30 \mathrm{~mA} \mathrm{~cm}$ at $1.23 \mathrm{~V}$ versus reversible hydrogen

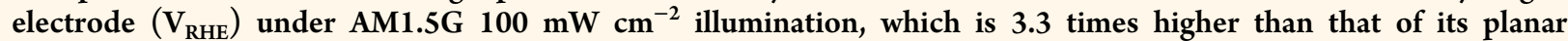
counterpart $\left(0.69 \mathrm{~mA} \mathrm{~cm} \mathrm{~cm}^{-2}\right.$ at $\left.1.23 \mathrm{~V}_{\mathrm{RHE}}\right)$. We further demonstrate that the optimized nanoporous photoanode exhibits an enhanced light-harvesting efficiency (LHE) of over 93\%, a high charge-separation efficiency $\left(\Phi_{\text {sep }}\right)$ of $38 \%$, and a high charge-injection efficiency $\left(\Phi_{\mathrm{ox}}\right)$ of $91 \%$ for water oxidation at $1.23 \mathrm{~V}_{\mathrm{RHE}}$, which are significantly outperforming those its planar counterpart $\left(\mathrm{LHE}=78 \%, \Phi_{\text {sep }}=28 \%\right.$, and $\Phi_{\text {ox }}=53 \%$ at $\left.1.23 \mathrm{~V}_{\mathrm{RHE}}\right)$. All of these properties of nanoporous $3 \mathrm{C}$-SiC enable a synergetic enhancement of solar water splitting performance. This work also brings insights into the design of other indirect band gap semiconductors for solar energy conversion.

KEYWORDS: nanoporous cubic silicon carbide (3C-SiC), photoelectrochemical water splitting, solar-to-hydrogen conversion, anodization, charge-separation efficiency

\section{INTRODUCTION}

Photoelectrochemical (PEC) water splitting is a promising approach to convert the intermittent solar radiation into a renewable, storable, and clean chemical energy in the form of hydrogen $\left(\mathrm{H}_{2}\right){ }^{1-9}$ To accomplish an efficient solar-to-hydrogen conversion in the PEC cell, the semiconductor photoelectrodes should meet certain criteria: (i) moderate band gap that can efficiently absorb visible sunlight to generate electrons and holes with enough energy to overcome the energetic barrier of water splitting, (ii) ideal band positions that straddle the water redox potentials, (iii) efficient carrier separation and transport before recombination, (iv) high activity for water splitting with low overpotential, and (v) long-term stability against corrosion in aqueous electrolytes. ${ }^{10-12}$ To date, there is no cost-effective single material which satisfies all of these requirements for solar water splitting. ${ }^{6,10-12}$ Most of the extensively studied materials

Received: January 10, 2021

Accepted: February 10, 2021

Published: February 19, 2021 
A

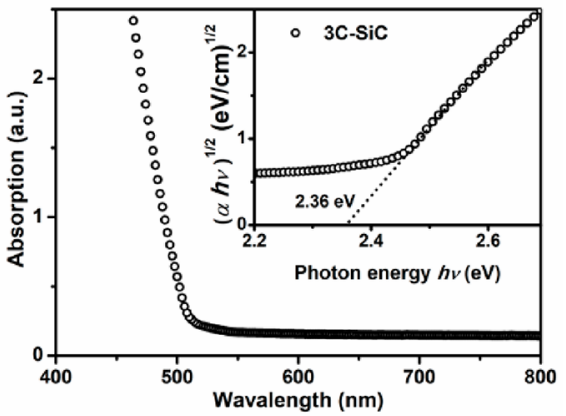

D

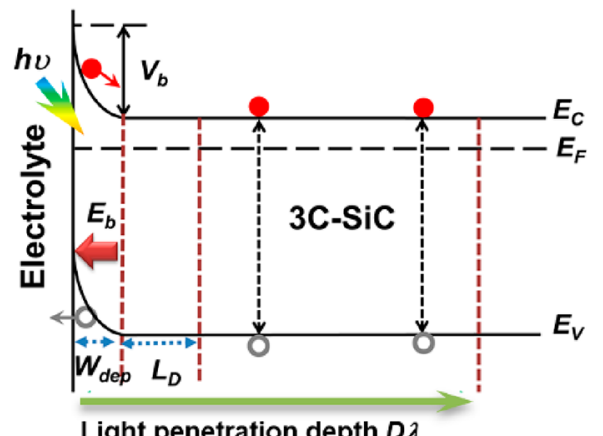

B

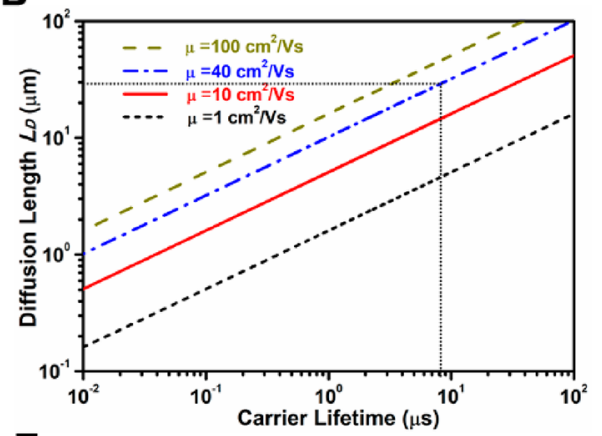

E

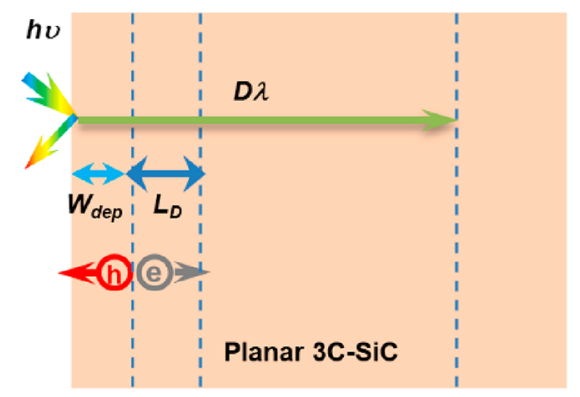

C

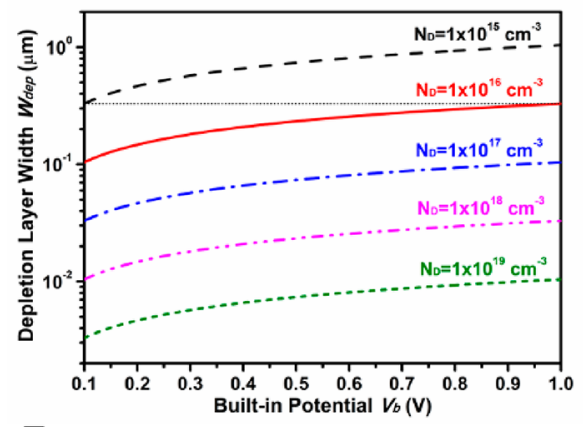

$\mathbf{F}$

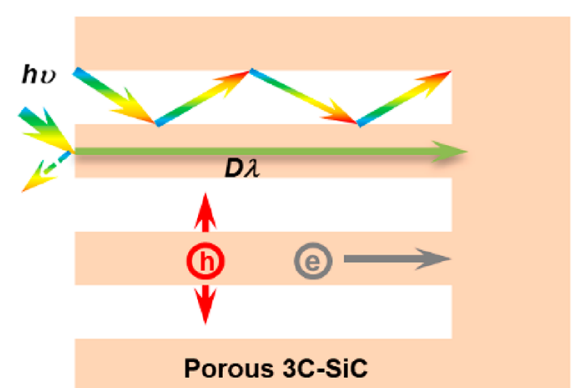

Figure 1. Drawback of planar 3C-SiC photoanodes. (A) Absorption spectrum and Tauc plot (inset) of high-quality 3C-SiC(111). (B) calculated diffusion length $\left(L_{\mathrm{D}}\right)$ as a function of the carrier lifetime $(\tau)$ with different hole mobilities $(\mu)$. (C) calculated width of space charge region $\left(W_{\text {dep }}\right)$ as a function of the built-in potentials $\left(V_{\mathrm{b}}\right)$ with different doping concentrations $\left(N_{\mathrm{D}}\right)$. (D) Schematic illustration of $W_{\text {dep }}, L_{\mathrm{D}}$, and light penetration depth $\left(D_{\lambda}\right)$ in $3 \mathrm{C}$-SiC photoanode. (E, F) schematic comparison of charge separation and diffusion in planar 3C-SiC and nanoporous $3 \mathrm{C}-\mathrm{SiC}$ photoanode.

such as $\mathrm{Si}, \mathrm{TiO}_{2}, \mathrm{Fe}_{2} \mathrm{O}_{3}, \mathrm{BiVO}_{4}, \mathrm{WO}_{3}, \mathrm{ZnO}$, II-VI, and III-V semiconductors exhibit either a too large band gap to harvest visible sunlight (e.g., $\mathrm{TiO}_{2}, \mathrm{ZnO}$, and so on) or unmatched band positions that are not able to oxidize or reduce water (e.g., $\mathrm{Si}$, $\mathrm{Fe}_{2} \mathrm{O}_{3}, \mathrm{BiVO}_{4}$, and $\mathrm{WO}_{3}$, etc.), or a poor stability in the electrolyte. ${ }^{13-18}$ In this regard, cubic silicon carbide (3C-SiC) has a relatively small band gap of $2.36 \mathrm{eV}$, which is close to the hypothetical ideal band gap $(2.03 \mathrm{eV})$ of a single material for a maximum of the solar water splitting efficiency. ${ }^{19}$ Most importantly, the conduction and valence band positions of 3C-SiC ideally straddle the water redox potentials, indicating that the photogenerated carriers have enough energy to overcome the energetic barrier of water splitting without applying any external bias. ${ }^{20-22}$

However, 3C-SiC, as a photoelectrode material, has not been well studied due to a lack of high-quality materials. ${ }^{22}$ Recently, Kato and co-workers reported that a photocathode fabricated using the p-type $3 \mathrm{C}$-SiC epilayer grown on $4 \mathrm{H}$-SiC by chemical vapor deposition and coated with $\mathrm{Pt}$ nanoparticles exhibited a promising water reduction performance, which achieved a solarto-hydrogen $(\mathrm{STH})$ conversion efficiency of $0.52 \% .^{23}$ They further demonstrated that the $3 \mathrm{C}-\mathrm{SiC} \mathrm{p}-\mathrm{n}$ junction photocathode coated with $\mathrm{Pt}$ showed the STH efficiency of $0.72 \%{ }^{24}$ However, it is still quite challenging to employ n-type $3 \mathrm{C}-\mathrm{SiC}$ as a photoanode for the PEC water oxidation, which involves a four-electron process with higher energy barriers than the twoelectron water reduction reaction and thus is regarded as the bottleneck for the PEC water splitting. Like most of the other semiconductor photoanodes, n-type 3C-SiC suffers from photocorrosion (surface oxidation). ${ }^{20,21}$ Therefore, a protective layer on $3 \mathrm{C}-\mathrm{SiC}$ photoanodes is always required. Song et al. reported that a coating of $\mathrm{Pt}$ nanoparticles on the n-type 3C-SiC photoanode improved its PEC performance and protected the surface against photocorrosion. ${ }^{21}$

Recently, our group has demonstrated that high-quality ntype $3 \mathrm{C}-\mathrm{SiC}$ films can be grown by the sublimation technique. $^{25-27}$ By integrating efficient oxygen-evolutionreaction (OER) cocatalysts on $3 \mathrm{C}-\mathrm{SiC}$, we showed an enhanced water oxidation performance and improved stability of the $3 \mathrm{C}$ $\mathrm{SiC}$ photoanodes. ${ }^{28-30}$ However, we found that despite the coating of different OER cocatalysts such as nickel oxide, ${ }^{28}$ iron oxyhydroxide $(\mathrm{FeOOH}),{ }^{29,30}$ and nickel-iron oxyhydroxide $(\mathrm{Ni}: \mathrm{FeOOH})$ on $3 \mathrm{C}-\mathrm{SiC},{ }^{29}$ the photocurrent density $\left(J_{\mathrm{ph}}\right)$ was limited by a maximum value of $\sim 1.1 \mathrm{~mA} \mathrm{~cm}^{-2}$ at $1.23 \mathrm{~V}$ versus reversible hydrogen electrode $\left(\mathrm{V}_{\mathrm{RHE}}\right)$ under $\mathrm{AM} 1.5 \mathrm{G} 100 \mathrm{~mW}$ $\mathrm{cm}^{-2}$ illumination (Supporting Information Table S1), which is still far below the maximum theoretical $J_{\mathrm{ph}}$ value of $8.0 \mathrm{~mA} \mathrm{~cm}{ }^{-2}$. Given the fact that $3 \mathrm{C}-\mathrm{SiC}$ is an indirect band gap material, we believe one of the major factors limiting $J_{\mathrm{ph}}$ is a relatively small absorption coefficient of $3 \mathrm{C}-\mathrm{SiC}$. This would result in a large light penetration depth compared to the carrier diffusion length and space charge width. As a result, most of the photogenerated electron-hole pairs are distributed in the neutral region and recombine there, thus limiting the photon-conversion efficiency. Another factor is that the smooth surface of the as-grown planar $3 \mathrm{C}$-SiC also reflects part of the sunlight, which limits the lightharvesting efficiency. To overcome these drawbacks, we propose to fabricate the nanoporous $3 \mathrm{C}$-SiC photoanode for improving its $\mathrm{PEC}$ water splitting performance. During the past decades, it has been extensively demonstrated that a large variety of nanostructured or porous-structured semiconductor photoelectrodes such as $\mathrm{Si}, \mathrm{Fe}_{2} \mathrm{O}_{3}, \mathrm{BiVO}_{4}$, and $\mathrm{ZnO}$, etc., could efficiently promote light harvesting, facilitate charge diffusion, and increase the active surface area, thus significantly enhancing 


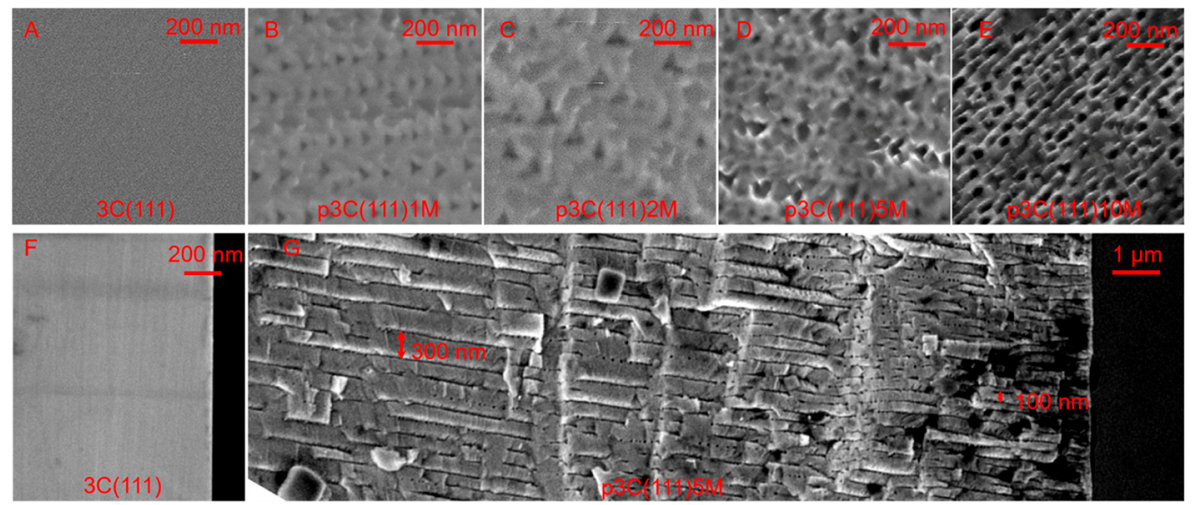

Figure 2. Morphologies of nanoporous 3C-SiC(111). Top-view SEM images of the planar $3 \mathrm{C}(111)(\mathrm{A})$ and nanoporous $\mathrm{p} 3 \mathrm{C}(111) x \mathrm{M}$, where $x \mathrm{M}$ represents the anodization times of $1,2,5$, and $10 \mathrm{~min}$, respectively $(\mathrm{B}-\mathrm{E})$. Comparison of the cross-sectional SEM images of the planar $3 \mathrm{C}(111)$ (F) and nanoporous $\mathrm{p} 3 \mathrm{C}(111) 5 \mathrm{M}(\mathrm{G})$.

the PEC water splitting performance. ${ }^{7,12,16,18}$ Although 3C-SiC exhibits promising properties for solar water splitting due to its relatively small band gap $(2.36 \mathrm{eV})$ and its ideal energy band positions that straddle the water redox potentials, the fabrication of nanoporous $3 \mathrm{C}-\mathrm{SiC}$ as an efficient photoelectrode for solar water splitting remains unexplored.

In this work, we showed a facile anodization method to fabricate nanoporous $3 \mathrm{C}-\mathrm{SiC}(111)$ and $3 \mathrm{C}-\mathrm{SiC}(001)$ photoanodes. In both cases, we demonstrated that, with coating of $\mathrm{Ni}: \mathrm{FeOOH}$ as the OER cocatalyst and the protection layer, the resulting nanoporous photoanodes significantly enhanced lightharvesting efficiency, charge-separation efficiency, and chargeinjection efficiency for water oxidation, thus evidently improving the overall PEC water splitting performance. The optimized nanoporous $3 \mathrm{C}-\mathrm{SiC}(111)$ photoanode achieved a high photocurrent density of $2.30 \mathrm{~mA} \mathrm{~cm}{ }^{-2}$ at $1.23 \mathrm{~V}_{\mathrm{RHE}}$ under AM1.5G $100 \mathrm{~mW} \mathrm{~cm}^{-2}$ illumination, which significantly outperforms its planar counterpart $\left(0.69 \mathrm{~mA} \mathrm{~cm}^{-2}\right.$ at $\left.1.23 \mathrm{~V}_{\mathrm{RHE}}\right)$. To our knowledge, such PEC water splitting photocurrent is the highest value ever reported for $3 \mathrm{C}-\mathrm{SiC}$ as a photoanode under AM1.5G $100 \mathrm{~mW} \mathrm{~cm}^{-2}$ illumination (Table S1).

\section{RESULTS AND DISCUSSION}

Drawback of Planar 3C-SiC Photoanodes. Figure 1A shows the absorption spectrum of a $300 \mu \mathrm{m}$ thick freestanding $3 \mathrm{C}-\mathrm{SiC}(111)$ sample grown by sublimation epitaxy, ${ }^{26,27}$ which exhibits a sharp band-edge absorption. The Tauc plot shown in the inset of Figure 1A yields an optical band gap of $2.36 \mathrm{eV}$, which is consistent with the reported band gap of $3 \mathrm{C}-\mathrm{SiC} .{ }^{31}$ Due to the nature of an indirect band gap semiconductor, 3C-SiC exhibits a smaller absorption coefficient $(\alpha)$ than direct band gap materials. Patrick and Choyke reported that the absorption coefficient of the n-type $3 \mathrm{C}$-SiC crystal is $\sim 63 \mathrm{~cm}^{-1}$ at $2.375 \mathrm{eV}$, giving rise to a rather large light penetration depth $\left(D_{\lambda}=1 / \alpha\right)$ of $159 \mu \mathrm{m}$ at $2.375 \mathrm{eV}(522 \mathrm{~nm}) .{ }^{32}$ Solangi and Chaudhry reported that the absorption coefficient of the n-type 3C-SiC epilayer (doping density is $5 \times 10^{16} \mathrm{~cm}^{-3}$ ) grown on $\mathrm{Si}$ is around $\sim 100$ $\mathrm{cm}^{-1}$ at $2.4 \mathrm{eV}$, which gives $D_{\lambda} \sim 100 \mu \mathrm{m}$ at $2.4 \mathrm{eV}$. ${ }^{33}$ These results indicate that at least a $100 \mu \mathrm{m}$ thick $3 \mathrm{C}$-SiC layer is required to fully absorb the sunlight with photon energies larger than its band gap. However, only the photogenerated electrons and holes in the space charge region and the diffusion length region can be separated by the built-in electric field $\left(E_{\mathrm{b}}\right)$ and thus be harvested for PEC water splitting. For the photoanode, the carrier diffusion length $\left(L_{\mathrm{D}}\right)$ and the width of space charge region $\left(W_{\text {dep }}\right)$ are given by

$$
\begin{aligned}
& L_{\mathrm{D}}=\sqrt{\mu \tau k_{\mathrm{B}} T / e} \\
& W_{\mathrm{dep}}=\sqrt{2 \varepsilon_{s} \varepsilon_{0} V_{\mathrm{b}} /\left(e N_{\mathrm{D}}\right)}
\end{aligned}
$$

where $\mu$ is the hole mobility, $\tau$ is the hole lifetime, $k_{\mathrm{B}} T / e$ is the product of the Boltzmann constant and the temperature divided by the elementary charge, $\varepsilon_{\mathrm{s}}$ is the dielectric constant of $3 \mathrm{C}$-SiC, $\varepsilon_{0}$ is the vacuum permittivity, $V_{\mathrm{b}}$ is the built-in potential, and $N_{\mathrm{D}}$ is the donor concentration.

We calculated $L_{\mathrm{D}}$ of $3 \mathrm{C}-\mathrm{SiC}$ as a function of hole lifetimes (Figure $1 \mathrm{~B}$ ). The reported hole mobility in $3 \mathrm{C}-\mathrm{SiC}$ ranges from 1 to $40 \mathrm{~cm}^{2} \mathrm{~V}^{-1} \mathrm{~s}^{-1} \cdot 34,35$ Due the presence of structural defects, $3 \mathrm{C}-\mathrm{SiC}$ commonly exhibits rather short hole lifetimes from a few to $120 \mathrm{~ns} .{ }^{36}$ Recently, we have demonstrated that high-quality $3 \mathrm{C}-\mathrm{SiC}$ grown by sublimation epitaxy exhibits a long hole lifetime of $8.2 \mu \mathrm{s} .{ }^{25}$ With the reported highest hole mobility (40 $\left.\mathrm{cm}^{2} \mathrm{~V}^{-1} \mathrm{~s}^{-1}\right)$ and the lifetime $(8.2 \mu \mathrm{s})$, the maximum value of $L_{\mathrm{D}}$ is calculated to be $29.1 \mu \mathrm{m}$ (Figure 1B). Due to a background nitrogen doping, the typical donor concentration in $3 \mathrm{C}-\mathrm{SiC}$ is around $\sim 1 \times 10^{16} \mathrm{~cm}^{-3}$, giving rise to a $W_{\text {dep }}$ of $0.3 \mu \mathrm{m}$ with an assumption of the $V_{\mathrm{b}}$ as high as $1 \mathrm{~V}$ (Figure 1C). Therefore, the maximum value of $W_{\text {dep }}+L_{\mathrm{D}}$ is estimated to be $29.4 \mu \mathrm{m}$, which is much smaller than the light penetration depth of $\sim 100 \mu \mathrm{m}$ at 2.4 $\mathrm{eV}$. This indicates that most photogenerated carriers in 3C-SiC are distributed within the neutral region and recombine there (Figure $1 \mathrm{D}, \mathrm{E}$ ), thus resulting in a relatively small photocurrent. To overcome this drawback of the planar photoanode, nanoporous $3 \mathrm{C}-\mathrm{SiC}$ is proposed in this work. As shown in Figure $1 \mathrm{~F}$, independent of the large light penetration depth, the nanoporous $3 \mathrm{C}-\mathrm{SiC}$ photoanode would shorten the distance for the hole transfer and enable hole transfer through different directions, thus improving the charge-separation efficiency. Moreover, the nanoporous structure would also reduce light reflection due to a light trapping effect and provide a large active surface for PEC reaction. These properties are expected to significantly increase the PEC water splitting efficiency.

Nanoporous 3C-SiC(111) Photoanodes. To demonstrate the advantages of the proposed nanoporous $3 \mathrm{C}-\mathrm{SiC}$ for solar water splitting, we prepared nanoporous $3 \mathrm{C}-\mathrm{SiC}(111)$ by a facile anodization method as described in Methods. The resulting samples are denoted as $\mathrm{p} 3 \mathrm{C}(111) x \mathrm{M}$, where $x \mathrm{M}$ represents the anodization times of $1,2,5$, and $10 \mathrm{~min}$, respectively. The scanning electron microscopy (SEM) images shown in Figure 2 

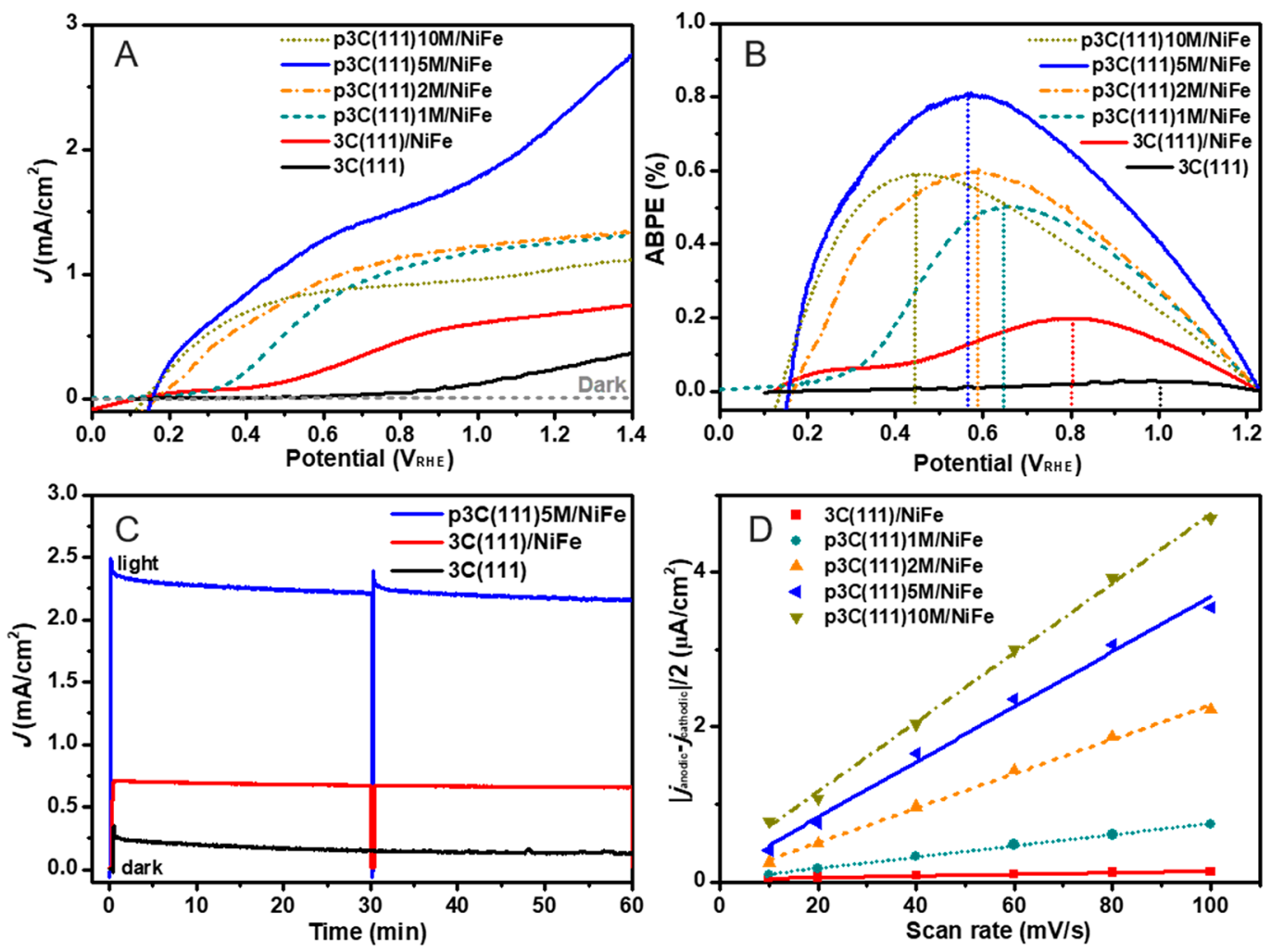

Figure 3. PEC water oxidation performance of planar and nanoporous 3C-SiC $(111)$ photoanodes. Current density-potential $(J-V)$ curves $(A)$ and $\mathrm{ABPE}(\mathrm{B})$ of planar $3 \mathrm{C}(111)$, planar $3 \mathrm{C}(111) / \mathrm{NiFe}$, and nanoporous $\mathrm{p} 3 \mathrm{C}(111) x \mathrm{M} / \mathrm{NiFe}$ photoanodes, where $x \mathrm{M}$ represents the anodization times of $1,2,5$, and $10 \mathrm{~min}$, respectively. (C) Photocurrent density-time $(J-t)$ curves of $3 \mathrm{C}(111), 3 \mathrm{C}(111) / \mathrm{NiFe}$, and $\mathrm{p} 3 \mathrm{C}(111) 5 \mathrm{M} / \mathrm{NiFe}$ photoanodes at $1.23 \mathrm{~V}_{\mathrm{RHE}}$ under illumination. All of the PEC measurements were carried out in $1.0 \mathrm{M} \mathrm{NaOH}$ electrolyte under AM1.5G $100 \mathrm{~mW} \mathrm{~cm}{ }^{-2}$ illumination. (D) Plots of $\left(j_{\text {anodic }}-j_{\text {cathodic }} / / 2\right)$ at $0.55 \mathrm{~V}_{\mathrm{RHE}}$ as a function of the scan rate, showing the extraction of double-layer capacitance $\left(C_{\mathrm{dl}}\right)$ for $3 \mathrm{C}(111) / \mathrm{NiFe}$ and $\mathrm{p} 3 \mathrm{C}(111) x \mathrm{M} / \mathrm{NiFe}$ photoanodes. The lines show the linear fitting plots, whose slopes correspond to $C_{\mathrm{dl}}$ according to the equation $C_{\mathrm{dl}}=I /(\mathrm{d} v / \mathrm{d} t)$.

compare morphologies of planar $3 \mathrm{C}(111)$ and nanoporous $\mathrm{p} 3 \mathrm{C}(111) x \mathrm{M}$. With increasing the anodization time from 1 to 5 min, the parallelly arranged triangle-shaped holes were formed and enlarged on the surface of $3 \mathrm{C}-\mathrm{SiC}(111)$. The formation of triangle-shaped holes is related to the $\langle 111\rangle$ orientation. However, after $10 \mathrm{~min}$ anodization, the sample showed very dense interconnected holes and the triangle shape disappeared. This is probably due to the severe etching. The cross-sectional SEM images show the prolongation of anodization time increases the depth of the porous layer, which is about 5.6, 12.6, 24.1, and $25.4 \mu \mathrm{m}$ after anodization of $1,2,5,10 \mathrm{~min}$, respectively (Figure $\mathrm{S} 1$ ). A high magnification of the crosssectional SEM of p3C(111)5M shows the columnar pore structure, with the diameter of columns gradually increasing from $100 \mathrm{~nm}$ near the surface to $300 \mathrm{~nm}$ inside the material (Figure 1G). However, the sample with $10 \mathrm{~min}$ anodization exhibits very large voids in the outermost $\sim 10 \mu \mathrm{m}$ thick layer (Figure S1D), indicating the deterioration of the crystalline quality due to severe anodization etching.

To compare planar and nanoporous $3 \mathrm{C}(111)$ photoanodes and protect them against photocorrosion, we deposited $\mathrm{Ni}: \mathrm{FeOOH}$ as the OER cocatalyst on these photoanodes at the same time. The prepared planar and nanoporous photoanodes are denoted as $3 \mathrm{C}(111) / \mathrm{NiFe}$ and $\mathrm{p} 3 \mathrm{C}(111) \times \mathrm{M} / \mathrm{NiFe}$, respectively. The $\mathrm{Ni}: \mathrm{FeOOH}$, as a cheap and earth-abundant material, has been widely used as an efficient and stable OER cocatalyst for PEC water splitting, especially in alkaline conditions. $^{29,37,38}$ As seen in Figure S2, the Ni:FeOOH on planar $3 \mathrm{C}(111)$ is composed of a network-like layer with a thickness of $\sim 140 \mathrm{~nm}$. In contrast, on nanoporous p3C(111)5M/NiFe, Ni:FeOOH consists of a $160 \mathrm{~nm}$ thick layer of nanoparticles. This morphology difference is probably due to the size confinement of the $\mathrm{Ni}: \mathrm{FeOOH}$ nucleation in the nanoporous structure. The cross-sectional SEM image of $\mathrm{p} 3 \mathrm{C}(111) 5 \mathrm{M} / \mathrm{NiFe}$ and its energy-dispersive X-ray spectroscopy (EDXS) and the elemental mapping measurements confirm that $\mathrm{Ni}: \mathrm{FeOOH}$ is also deposited inside of the pore structures (Figure S2I-M). As seen in Figure S2H,M, the EDXS spectra collected on the surface and the pore structure of p3C(111)5M/ $\mathrm{NiFe}$ show similar $\mathrm{Ni}, \mathrm{Fe}$, and $\mathrm{O}$ signals. Meanwhile, the ratio of $\mathrm{Ni}$ and Fe elements detected by EDXS analysis is around 8:100, which is close to the reported optimal ratio of $\mathrm{Ni}: \mathrm{FeOOH}$ cocatalyst. ${ }^{37}$ The X-ray diffraction (XRD) patterns of 3C(111)/ $\mathrm{NiFe}$ and $\mathrm{p} 3 \mathrm{C}(111) 5 \mathrm{M} / \mathrm{NiFe}$ display identical diffraction peaks, corresponding to the $\beta$-FeOOH phases (Figure S3). ${ }^{37,39}$

The PEC water splitting performances of the planar $3 \mathrm{C}(111)$, $3 \mathrm{C}(111) / \mathrm{NiFe}$, and nanoporous $\mathrm{p} 3 \mathrm{C}(111) x \mathrm{M} / \mathrm{NiFe}$ photoanodes were measured in $1.0 \mathrm{M} \mathrm{NaOH}$ electrolyte under AM1.5G $100 \mathrm{~mW} \mathrm{~cm}^{-2}$ illumination. As seen in Figures 3A and S4 ( $J-V$ curves under chopped 1 sun illumination), with a coating of $\mathrm{Ni}: \mathrm{FeOOH}$ cocatalyst, the $3 \mathrm{C}(111) / \mathrm{NiFe}$ photoanode significantly reduced the onset potential $\left(E_{\text {onset }}\right)$ and enhanced the photocurrent density $\left(J_{\mathrm{ph}}\right)$ compared to pristine $3 \mathrm{C}-\mathrm{SiC}(111)$, indicating that $\mathrm{Ni} F \mathrm{FeOOH}$ boosts the OER activity. As proposed, the nanoporous $3 \mathrm{C}(111) x \mathrm{M} / \mathrm{NiFe}$ photoanodes dramatically enhanced the photocurrent density 
Table 1. PEC Water Splitting Performance of Planar 3C(111), Planar 3C(111)/NiFe, and Nanoporous p3C(111)xM/NiFe Photoanodes, Where $x M$ Represents the Anodization Times of 1, 2, 5, and 10 min, Respectively ${ }^{a}$

\begin{tabular}{|c|c|c|c|c|c|c|c|c|c|}
\hline sample & $\begin{array}{c}J \text { at } 1.23 \mathrm{~V}_{\mathrm{RHE}} \\
\left(\mathrm{mA} \mathrm{cm} \mathrm{cm}^{-2}\right)\end{array}$ & $\begin{array}{c}E_{\text {onset }} \\
\left(\mathrm{V}_{\mathrm{RHE}}\right)\end{array}$ & $\begin{array}{c}\max A B P E \\
(\%)\end{array}$ & $\begin{array}{c}E_{\max } \text { at } \mathrm{ABPE}_{\max } \\
\left(\mathrm{V}_{\mathrm{RHE}}\right)\end{array}$ & $\begin{array}{c}\mathrm{ff} \\
(\%)\end{array}$ & $\begin{array}{c}C_{\mathrm{dl}} \\
\left(\mu \mathrm{F} \mathrm{cm}^{-2}\right)\end{array}$ & $\begin{array}{l}\text { rel surf } \\
\text { area }\end{array}$ & $\begin{array}{c}\text { LHE at } 450 \mathrm{~nm} \\
(\%)\end{array}$ & $\begin{array}{c}J_{\mathrm{Abs}} \\
\left(\mathrm{mA} \mathrm{cm} \mathrm{cm}^{-2}\right)\end{array}$ \\
\hline planar 3C(111) & 0.25 & $\sim 0.4$ & 0.03 & 1.0 & 9 & & & & \\
\hline planar $3 \mathrm{C}(111) / \mathrm{NiFe}$ & 0.69 & $\sim 0.2$ & 0.20 & 0.80 & 29 & 1.05 & 1.0 & 78 & 4.67 \\
\hline $\mathrm{p} 3 \mathrm{C}(111) 1 \mathrm{M} / \mathrm{NiFe}$ & 1.26 & $\sim 0.2$ & 0.50 & 0.65 & 41 & 7.36 & 7.0 & 86 & 5.67 \\
\hline $\mathrm{p} 3 \mathrm{C}(111) 2 \mathrm{M} / \mathrm{NiFe}$ & 1.30 & $\sim 0.2$ & 0.60 & 0.58 & 47 & 22.20 & 21.1 & 90 & 6.28 \\
\hline $\mathrm{p} 3 \mathrm{C}(111) 5 \mathrm{M} / \mathrm{NiFe}$ & 2.30 & $\sim 0.2$ & 0.81 & 0.56 & 36 & 35.70 & 34.0 & 93 & 6.67 \\
\hline p3C(111)10M/NiFe & 1.05 & $\sim 0.2$ & 0.59 & 0.45 & 58 & 44.80 & 42.7 & 97 & 7.40 \\
\hline
\end{tabular}

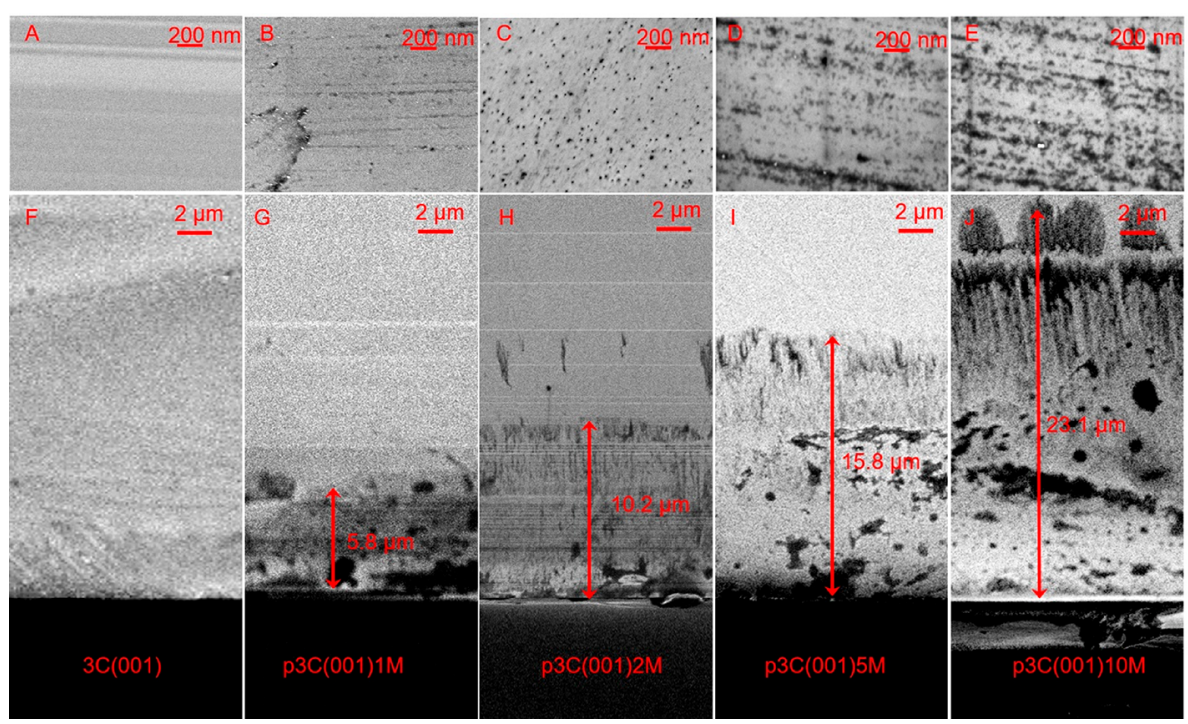

Figure 4. Morphologies of nanoporous $3 \mathrm{C}-\mathrm{SiC}(001)$. Top view $\mathrm{SEM}$ images of planar $3 \mathrm{C}(001)(\mathrm{A})$ and nanoporous $\mathrm{p} 3 \mathrm{C}(001) x \mathrm{M}(\mathrm{B}-\mathrm{E})$, where $x \mathrm{M}$ represents the anodization times of $1,2,5$, and $10 \mathrm{~min}$, respectively. Cross-sectional SEM images of planar $3 \mathrm{C}(001)(\mathrm{F})$ and nanoporous p3C $(001) x M(G-J)$.

compared to the planar counterpart (Figures 3A and S4; Table 1). With increasing the anodization times from 1 to $5 \mathrm{~min}$, the resulting photoanodes exhibited an increased photocurrent due to the increase of the porous layer depth. However, the photoanode with $10 \mathrm{~min}$ anodization showed a decreased photocurrent. This is probably caused by the deterioration of the outermost $3 \mathrm{C}-\mathrm{SiC}(111)$ due to severe anodization etching (Figure S1D). The p3C(111)5M/NiFe photoanode achieved the highest $J_{\mathrm{ph}}$ of $2.30 \mathrm{~mA} \mathrm{~cm}{ }^{-2}$ at $1.23 \mathrm{~V}_{\mathrm{RHE}}$, which is 3.3 times higher than that of the planar $3 \mathrm{C}(111) / \mathrm{NiFe}$ and the highest photocurrent among the reported values of $3 \mathrm{C}-\mathrm{SiC}$ photoanodes (see Table S1).

Moreover, the nanoporous $3 \mathrm{C}-\mathrm{SiC}$ photoanodes exhibited a much steeper increase of photocurrent than the planar counterpart. The p3C(111) $5 \mathrm{M} / \mathrm{NiFe}$ showed a precipitous photocurrent increase at as low as $\sim 0.2 \mathrm{~V}_{\mathrm{RHE}}$, which is a cathodic shift of $\sim 0.3 \mathrm{~V}$ compared to its planar counterpart 3C(111)/ $\mathrm{NiFe}$. This power characteristic can be clearly demonstrated by the fill factor (ff), which is defined as $\mathrm{ff}=J_{\mathrm{mp}}\left(1.23-V_{\mathrm{mp}}\right)$ / $\left[J_{\mathrm{sc}}\left(1.23-E_{\text {onset }}\right)\right]$, where $J_{\mathrm{mp}}$ and $V_{\mathrm{mp}}$ are the photocurrent density and potential at the maximum power point and $J_{\mathrm{sc}}$ is the photocurrent density at $1.23 \mathrm{~V}_{\mathrm{RHE}}$. As shown in Figure $\mathrm{S} 5$ and Table 1, the fill factors of the nanoporous photoanodes were substantially increased. Moreover, the potential at the maximum power point $\left(V_{\mathrm{mp}}\right)$ was decreased from $\sim 1.0 \mathrm{~V}_{\mathrm{RHE}}$ for the planar $3 \mathrm{C}(001)$ and $\sim 0.8 \mathrm{~V}_{\mathrm{RHE}}$ for the planar $3 \mathrm{C}(001) / \mathrm{NiFe}$ to $\sim 0.6$ $\mathrm{V}_{\mathrm{RHE}}$ for the nanoporous $3 \mathrm{C}(001) 5 \mathrm{M} / \mathrm{NiFe}$ (Figure S5).
Figure 3B shows the applied bias photon-to-current efficiency (ABPE) curves for the pristine $3 \mathrm{C}(111)$, planar $3 \mathrm{C}(111) / \mathrm{NiFe}$, and nanoporous $\mathrm{p} 3 \mathrm{C}(111) x \mathrm{M} / \mathrm{NiFe}$ photoanodes. $\mathrm{ABPE}$ is given by the following equation: $\mathrm{ABPE}=J_{\mathrm{ph}}\left(1.23-V_{\mathrm{app}}\right) /$ $P_{\mathrm{AM} 1.5 \mathrm{G}}$, where $P_{\mathrm{AM} 1.5 \mathrm{G}}$ is the light density of simulated sunlight (AM1.5G $100 \mathrm{~mW} \mathrm{~cm}^{-2}$ ). The nanoporous photoanodes demonstrated a significant enhancement of $A B P E$ and a reduced potential at the maximum ABPE. The p3C(111)5M/NiFe photoanode exhibited a maximum ABPE of $0.81 \%$ at a low applied potential of $0.56 \mathrm{~V}_{\mathrm{RHE}}$, which is the highest photoconversion efficiency ever reported for 3C-SiC photoanodes (Table S1). In contrast, the planar 3C(111)/NiFe showed much lower ABPE values of $0.20 \%$ at a higher applied potential of 0.80 $\mathrm{V}_{\text {RHE }}$ (Table 1).

The photocurrent density-time $(J-t)$ curves recorded at 1.23 $\mathrm{V}_{\mathrm{RHE}}$ for the planar $3 \mathrm{C}(111), 3 \mathrm{C}(111) / \mathrm{NiFe}$, and nanoporous p3C(111) $5 \mathrm{M} / \mathrm{NiFe}$ photoanodes are shown in Figure 3C. Under the 1 sun illumination for $60 \mathrm{~min}$, the $J_{\mathrm{ph}}$ of the planar $3 \mathrm{C}$ (111) photoanode decreased from 0.35 to $0.13 \mathrm{~mA} \mathrm{~cm}$, indicating a $63 \%$ loss of its initial $J_{\mathrm{ph}}$. It has been reported that $3 \mathrm{C}-\mathrm{SiC}$ photoanodes suffered from a photocorrosion, which is a surface oxidation reaction forming $\mathrm{SiO}_{2}\left(3 \mathrm{C}-\mathrm{SiC}+4 \mathrm{H}_{2} \mathrm{O}+8 \mathrm{~h}^{+}\right.$ $\left.\rightarrow \mathrm{SiO}_{2}+\mathrm{CO}_{2}+8 \mathrm{H}^{+}\right) \cdot{ }^{21}$ For the $\mathrm{p} 3 \mathrm{C}(111) 5 \mathrm{M} / \mathrm{NiFe}$ photoanode, the photocurrent retained $94 \%$ of its initial $J_{\mathrm{ph}}$ of $2.30 \mathrm{~mA} \mathrm{~cm}^{-2}$ after $60 \mathrm{~min}$ illumination. Meanwhile, the evolved $\mathrm{O}_{2}$ over the $\mathrm{p} 3 \mathrm{C}(111) 5 \mathrm{M} / \mathrm{NiFe}$ photoanode was detected by 

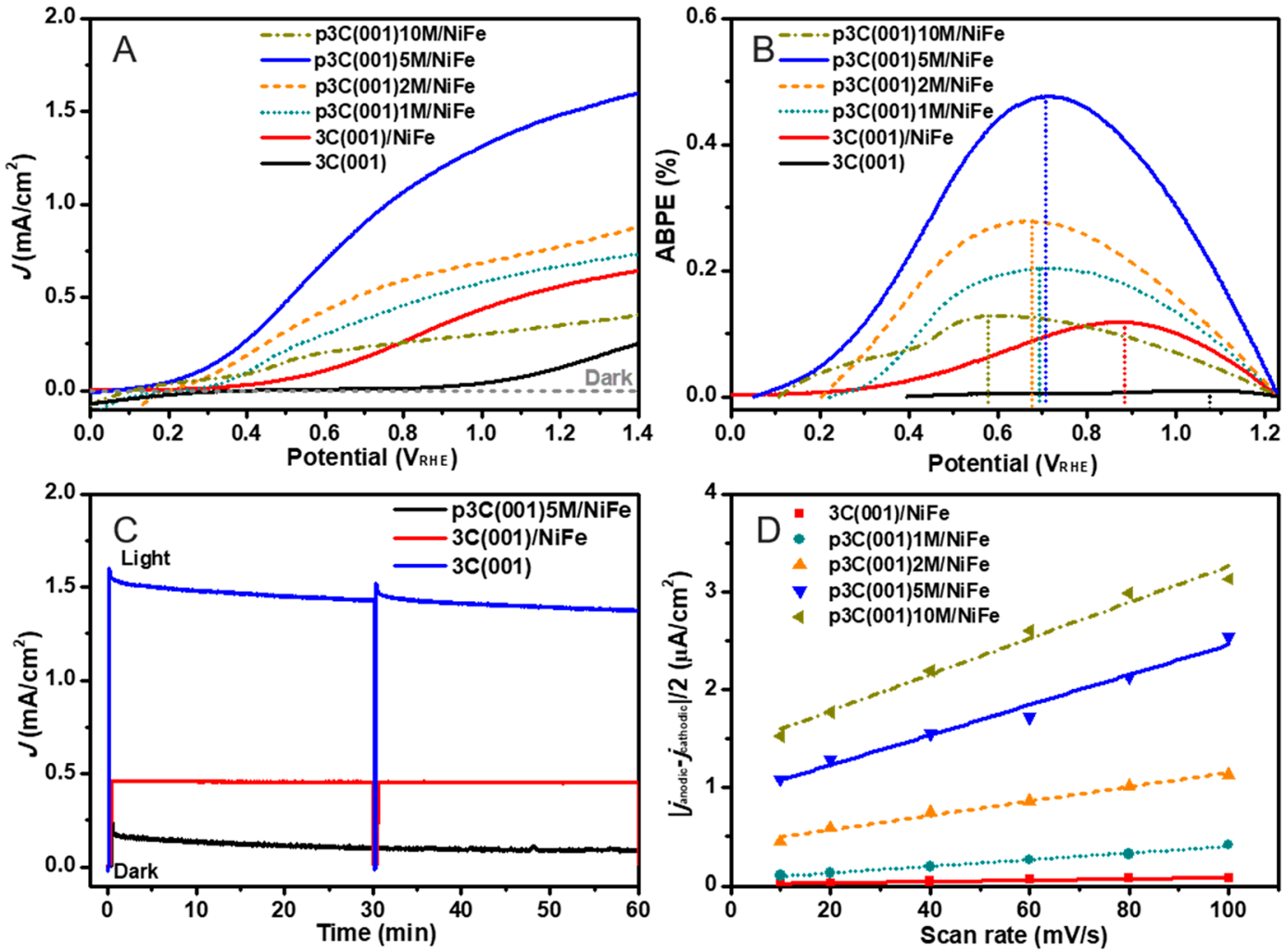

Figure 5. PEC water oxidation performance of planar and nanoporous $3 \mathrm{C}-\mathrm{SiC}(001)$ photoanodes. $J-V$ curves (A) and ABPE (B) of planar $3 \mathrm{C}(001)$, planar $3 \mathrm{C}(001) / \mathrm{NiFe}$, and nanoporous $\mathrm{p} 3 \mathrm{C}(001) x \mathrm{M} / \mathrm{NiFe}$ photoanodes, where $x \mathrm{M}$ represents the anodization times of $1,2,5$, and $10 \mathrm{~min}$, respectively. (C) $J-t$ curves of $3 \mathrm{C}(001)$, $3 \mathrm{C}(001) / \mathrm{NiFe}$ and $\mathrm{p} 3 \mathrm{C}(001) 5 \mathrm{M} / \mathrm{NiFe}$ photoanodes at $1.23 \mathrm{~V}_{\mathrm{RHE}}$ under illumination. All of the PEC measurements were carried out in $1.0 \mathrm{M} \mathrm{NaOH}$ electrolyte under AM1.5G $100 \mathrm{~mW} \mathrm{~cm}$ illumination. $^{-2}$ (D) Plots of $\left(l_{\text {anodic }}-j_{\text {cathodic }} / / 2\right)$ at $0.55 \mathrm{~V}_{\mathrm{RHE}}$ as a function of the scan rate, showing the extraction of double-layer capacitance $\left(C_{\mathrm{dl}}\right)$ for $3 \mathrm{C}(001) / \mathrm{NiFe}$ and $\mathrm{p} 3 \mathrm{C}(001) x \mathrm{M} / \mathrm{NiFe}$ photoanodes. The lines show the linear fitting plots, whose slopes correspond to $C_{\mathrm{dl}}$ according to the equation $C_{\mathrm{dl}}=I /(\mathrm{d} v / \mathrm{d} t)$.

Table 2. PEC Water Splitting Performance of Planar 3C(001), Planar 3C(001)/NiFe, and Nanoporous p3C(001)xM/NiFe Photoanodes, Where $x \mathrm{M}$ Represents the Anodization Times of 1, 2, 5, and $10 \mathrm{~min}$, Respectively ${ }^{a}$

\begin{tabular}{|c|c|c|c|c|c|c|c|c|c|}
\hline sample & $\begin{array}{c}J \text { at } 1.23 \mathrm{~V}_{\mathrm{RHE}} \\
\left(\mathrm{mA} \mathrm{cm}^{-2}\right)\end{array}$ & $\begin{array}{c}E_{\text {onset }} \\
\left(\mathrm{V}_{\mathrm{RHE}}\right)\end{array}$ & $\underset{(\%)}{\max A B P E}$ & $\begin{array}{c}V \text { at } \mathrm{ABPE}_{\max } \\
\left(\mathrm{V}_{\mathrm{RHE}}\right)\end{array}$ & $\underset{(\%)}{\mathrm{ff}}$ & $\begin{array}{c}C_{\mathrm{dl}} \\
\left(\mu \mathrm{F} \mathrm{cm}^{-2}\right)\end{array}$ & $\begin{array}{c}\text { rel surf } \\
\text { area }\end{array}$ & $\begin{array}{c}\text { LHE at } 450 \mathrm{~nm} \\
(\%)\end{array}$ & $\begin{array}{c}J_{\mathrm{Abs}} \\
\left(\mathrm{mA} \mathrm{cm} \mathrm{cm}^{-2}\right)\end{array}$ \\
\hline planar 3C(001) & 0.14 & $\sim 0.4$ & 0.01 & 1.07 & 8 & & & & \\
\hline planar $3 \mathrm{C}(001) / \mathrm{NiFe}$ & 0.58 & $\sim 0.2$ & 0.12 & 0.88 & 20 & 0.67 & 1.0 & 76 & 4.79 \\
\hline p3C(001)1M/NiFe & 0.68 & $\sim 0.2$ & 0.20 & 0.69 & 29 & 3.38 & 5.0 & 88 & 5.86 \\
\hline p3C(001)2M/NiFe & 0.79 & $\sim 0.2$ & 0.28 & 0.67 & 34 & 7.34 & 11.0 & 91 & 6.41 \\
\hline p3C(001)5M/NiFe & 1.50 & $\sim 0.2$ & 0.48 & 0.71 & 31 & 15.30 & 22.8 & 96 & 7.01 \\
\hline p3C(001)10M/NiFe & 0.36 & $\sim 0.2$ & 0.13 & 0.58 & 35 & 18.40 & 27.5 & 99 & 7.42 \\
\hline
\end{tabular}

gas chromatography and the Faradaic efficiency of $\mathrm{O}_{2}$ was determined to be $75 \%$ (Table S2).

To quantify the effective electrochemically active surface area, cyclic voltammetry measurements were employed to extract the double-layer capacitance $\left(C_{\mathrm{dl}}\right)$ of the planar and nanoporous photoanodes (Figure S6), according to the reported method. ${ }^{7,38,40}$ Figure 3D shows the plots of the half-difference of the anodic and cathodic current density $\left(\left|j_{\text {anodic }}-j_{\text {cathodic }}\right| / 2\right)$ at 0.55 $\mathrm{V}_{\mathrm{RHE}}$ as a function of the scan rate. The slopes of these linear plots gave rise to the geometric $C_{\mathrm{d},}$, which is proportional to the effective surface area of the photoanode. From a comparison of the extracted $C_{\mathrm{d}}$, we found that the electrochemically active surface area of the nanoporous photoanodes was significantly increased by increasing the anodization time, consistent with the increased depth of nanoporous layer. Notably, the surface area of
p3C(111)5M/NiFe is 34 times larger than that of the planar $3 \mathrm{C}(111) / \mathrm{NiFe}$ (Table 1$)$.

Nanoporous 3C-SiC(001) Photoanodes. The nanoporous $3 \mathrm{C}-\mathrm{SiC}(001)$ photoanodes were prepared by the anodization method using the same conditions as for nanoporous $3 \mathrm{C}-\mathrm{SiC}(111)$. The prepared samples are denoted as $\mathrm{p} 3 \mathrm{C}(001) x \mathrm{M}$, where $x \mathrm{M}$ represents the anodization times of 1 , 2,5 , and $10 \mathrm{~min}$, respectively. Figure 4 shows the morphologies of planar $3 \mathrm{C}(001)$ and nanoporous $\mathrm{p} 3 \mathrm{C}(001) x \mathrm{M}$. With increasing anodization time, more densely arranged holes on the $3 C(001)$ surface were clearly observed. Unlike $3 C(111)$, those holes do not show any triangular shape. The different shapes of etched holes on $3 C(111)$ and $3 C(001)$ are related to the different crystalline orientations. As the surface of the commercial $3 \mathrm{C}(001)$ wafer was mechanically polished, the anodization etching also boosts the scratches as seen in Figure 

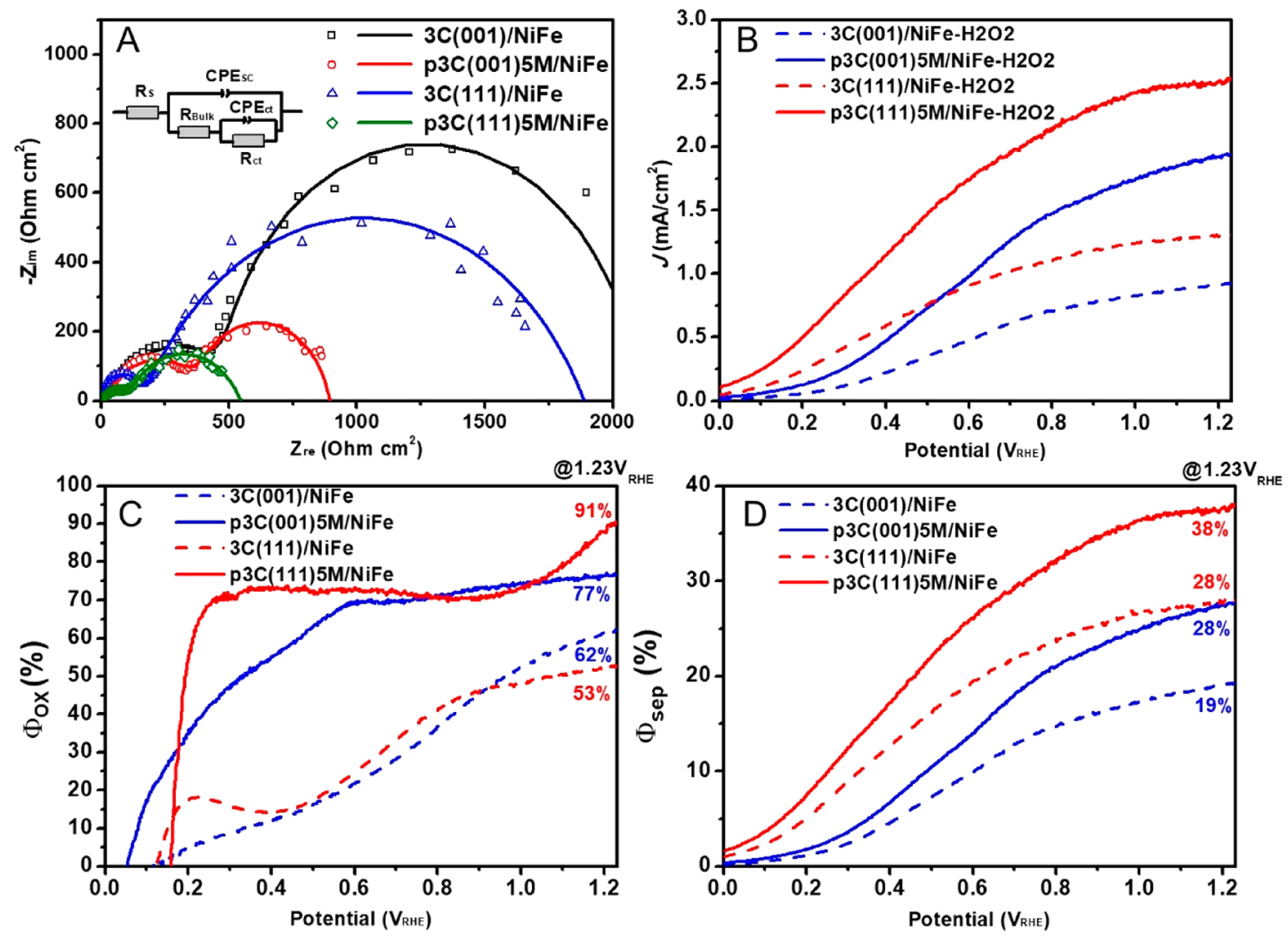

Figure 6. Effect of nanoporous structure of $3 \mathrm{C}-\mathrm{SiC}$ on the charge transport properties, charge-separation efficiency $\left(\Phi_{\text {sep }}\right)$, and charge-injection efficiency into electrolyte for oxidation reaction $\left(\Phi_{\text {ox }}\right)$. (A) Nyquist plots of the $3 \mathrm{C}(001) / \mathrm{NiFe}, \mathrm{p} 3 \mathrm{C}(001) 5 \mathrm{M} / \mathrm{NiFe}, 3 \mathrm{C}(111) / \mathrm{NiFe}$, and p3C(111)5M/NiFe photoanodes, measured from 1 to $10^{5} \mathrm{~Hz}$ at $1.23 \mathrm{~V}_{\mathrm{RHE}}$ under AM1.5 $100 \mathrm{~mW} \mathrm{~cm}{ }^{-2}$ illumination. Panel A inset: equivalent circuit used for fitting the impedance data. (B) $J-V$ curves of the $3 \mathrm{C}(001) / \mathrm{NiFe}, \mathrm{p} 3 \mathrm{C}(001) 5 \mathrm{M} / \mathrm{NiFe}, 3 \mathrm{C}(111) / \mathrm{NiFe}$, and $\mathrm{p} 3 \mathrm{C}(111) 5 \mathrm{M} / \mathrm{NiFe}$ photoanodes in $1.0 \mathrm{M} \mathrm{NaOH}$ electrolyte with $5 \% \mathrm{H}_{2} \mathrm{O}_{2}$ as the hole scavenger under 1 sun illumination. $\Phi_{\mathrm{ox}}(\mathrm{C})$ and $\Phi_{\text {sep }}(\mathrm{D})$ as a function of the potential $\mathrm{V}_{\mathrm{RHE}}$ for the $3 \mathrm{C}(001) / \mathrm{NiFe}, \mathrm{p} 3 \mathrm{C}(001) 5 \mathrm{M} / \mathrm{NiFe}, 3 \mathrm{C}(111) / \mathrm{NiFe}$, and $\mathrm{p} 3 \mathrm{C}(111) 5 \mathrm{M} / \mathrm{NiFe}$ photoanodes.

4D,E. From the cross-sectional SEM images, the depths of the nanoporous layer are 5.8, 10.2, 15.8, and $23.1 \mu \mathrm{m}$ for the samples after 1, 2, 5, and $10 \mathrm{~min}$ of anodization (Figure 4G-J). Similar to nanoporous 3C-SiC(111), 10 min anodization also resulted in large voids in the outermost layer, indicating the deterioration of the crystalline quality. To evaluate the PEC performance of the nanoporous $3 \mathrm{C}-\mathrm{SiC}(001)$ photoanodes, we employed the same conditions as used for $3 \mathrm{C}-\mathrm{SiC}(111)$ to deposit $\mathrm{Ni}: \mathrm{FeOOH}$ on $3 \mathrm{C}(001)$ and $\mathrm{p} 3 \mathrm{C}(001) x \mathrm{M}$ photoanodes at the same time, hereby denoted as $3 \mathrm{C}(001) / \mathrm{NiFe}$ and $\mathrm{p} 3 \mathrm{C}(001) x \mathrm{M} / \mathrm{NiFe}$, respectively. As for the planar case, the deposited $\mathrm{Ni}: \mathrm{FeOOH}$ on $3 \mathrm{C}(001)$ exhibited the same network-like layer as on $3 \mathrm{C}(111)$, as seen in Figure S7A. For the nanoporous case, the Ni:FeOOH on $\mathrm{p} 3 \mathrm{C}(001) 5 \mathrm{M}$ showed a nanoparticle morphology (Figure $\mathrm{S} 7 \mathrm{G})$, identical to that on $\mathrm{p} 3 \mathrm{C}(111) 5 \mathrm{M}$. In both cases, the thicknesses of $\mathrm{Ni}: \mathrm{FeOOH}$ are similar to those on $3 \mathrm{C}(111)$. The EDXS and the elemental mapping results confirmed that $\mathrm{Ni}: \mathrm{FeOOH}$ was also deposited into the pore structure of nanoporous 3C(001), as shown in Figure S7.

Figures 5 and $S 8$ ( $J-V$ curves under chopped 1 sun illumination) show the PEC water splitting results of the planar $3 \mathrm{C}(001) / \mathrm{NiFe}$ and nanoporous $3 \mathrm{C}(001) x \mathrm{M} / \mathrm{NiFe}$ photoanodes, which are quite similar to the PEC results of the corresponding 3C(111) photoanodes. The nanoporous $3 \mathrm{C}(001) x \mathrm{M} / \mathrm{NiFe}$ photoanodes exhibit enhanced ABPE, ff values, and surface area (Table 2 and Figures S9 and S10), but their overall $\mathrm{PEC}$ performance is lower than that of the nanoporous $3 \mathrm{C}(111)$. Among all $3 \mathrm{C}(001) x \mathrm{M} / \mathrm{NiFe}$ photo- anodes, p3C (001) $5 \mathrm{M} / \mathrm{NiFe}$ gives the highest photocurrent of $1.50 \mathrm{~mA} \mathrm{~cm}^{-2}$ at $1.23 \mathrm{~V}_{\mathrm{RHE}}$, which is 2.6 times higher than that of the planar $3 \mathrm{C}(001) / \mathrm{NiFe}$ photoanode (Table 2) but still lower than the photocurrent $\left(2.30 \mathrm{~mA} \mathrm{~cm}{ }^{-2}\right)$ of $\mathrm{p} 3 \mathrm{C}(111) 5 \mathrm{M} / \mathrm{NiFe}$ prepared at the same conditions. Moreover, electrochemically active surface areas of $\mathrm{p} 3 \mathrm{C}(001) x \mathrm{M} / \mathrm{NiFe}$ are respectively smaller than the corresponding $\mathrm{p} 3 \mathrm{C}(111) x \mathrm{M} / \mathrm{NiFe}$ fabricated under the same conditions (Table 2). This result is probably due to the presence of the columnar pore structures in nanoporous $\mathrm{p} 3 \mathrm{C}(111) x \mathrm{M} / \mathrm{NiFe}$ (Figure $2 \mathrm{G}$ ), which might provide larger electrochemically active surface areas.

Understanding the Improvement in PEC Performance of Nanoporous 3C-SiC Photoanodes. To understand the significant improvement of the PEC water splitting performance of nanoporous $3 \mathrm{C}-\mathrm{SiC}$ with respect to the planar counterparts, the electrochemical impedance spectroscopy (EIS) was measured at $1.23 \mathrm{~V}_{\mathrm{RHE}}$ under AM1.5G, $100 \mathrm{~mW} \mathrm{~cm}{ }^{-2}$ illumination in the frequency range of $1-10^{5} \mathrm{~Hz}$. The Nyquist plots of all $3 \mathrm{C}(111) / \mathrm{NiFe}, \mathrm{p} 3 \mathrm{C}(111) 5 \mathrm{M} / \mathrm{NiFe}, 3 \mathrm{C}(001) /$ $\mathrm{NiFe}$, and $\mathrm{p} 3 \mathrm{C}(001) 5 \mathrm{M} / \mathrm{NiFe}$ photoanodes exhibited two semicircles (Figure 6A), which were fitted by the equivalent circuit consisting of the series resistance $\left(R_{s}\right)$, the charge-transfer resistance $\left(R_{\text {bulk }}\right)$ and the capacitance $\left(\mathrm{CPE}_{\mathrm{SC}}\right)$ in the bulk of the photoanode, and the charge-transfer resistance from the photoanode to electrolyte $\left(R_{\mathrm{ct}}\right)$ and the corresponding capacitance $\left.\left(\mathrm{CPE}_{\mathrm{ct}}\right)\right)^{41}$ The fitting results are listed in Table S3.

For the planar photoanodes, $R_{\text {bulk }}$ in $3 \mathrm{C}(111) / \mathrm{NiFe}$ is 3.4 times lower than that in $3 \mathrm{C}(001) / \mathrm{NiFe}$. This result can be 
explained by the higher crystalline quality of $3 \mathrm{C}-\mathrm{SiC}(111)$, thus less charge recombinations in bulk compared to $3 \mathrm{C}-\mathrm{SiC}(001)$, as confirmed by our previous work. ${ }^{25,26} \mathrm{We}$ find that the XRD $\omega$ rocking curves of $3 \mathrm{C}-\mathrm{SiC}(111)$ showed an average of the full width at half-maximum (fwhm) of 38 arcsec, which is 2.8 times smaller than that of $3 \mathrm{C}-\mathrm{SiC}(001)$ measured under the same condition $($ fwhm $=105$ arcsec for $3 \mathrm{C}-\mathrm{SiC}(001)) \cdot{ }^{26,28} \mathrm{In}$ particular, from the low-temperature $(2 \mathrm{~K})$ photoluminescence measurement, we have observed the radiative emissions from up to four bound excitons in our high-quality $3 \mathrm{C}-\mathrm{SiC}(111)$ material, indicating a suppressed nonradiative recombination and thus a longer carrier lifetime. ${ }^{25}$ The microwave photoconductivity decay measurements further confirmed that a long carrier lifetime of $8.2 \mu$ s was observed in our high-quality $3 \mathrm{C}$ $\mathrm{SiC}(111)$, which is much longer than reported carrier lifetimes (a few to $120 \mathrm{~ns}$ ) in $3 \mathrm{C}-\mathrm{SiC}(001)$ grown on Si substrates. $^{25}$

For the nanoporous photoanodes, both p3C(111)5M/NiFe and $\mathrm{p} 3 \mathrm{C}(001) 5 \mathrm{M} / \mathrm{NiFe}$ significantly reduce $R_{\text {bulk }}$ and $R_{\mathrm{ct}}$ compared to their planar counterparts (Table S3), which in turn explains their dramatic enhancement in the PEC performance. As expected, the nanoporous structure shortens the distances for charge transfer, provides a significantly enlarged surface area (see Tables 1 and 2), and increases the number of the catalytic sites for water oxidation, thus reducing both $R_{\text {bulk }}$ and $R_{\mathrm{ct}}$.

The reflectance and transmittance spectra of the planar and nanoporous photoanodes were measured to extract their lightharvesting efficiency (LHE). As seen in Figures S11 and S12, both nanoporous $3 \mathrm{C}(111) x \mathrm{M} / \mathrm{NiFe}$ and $3 \mathrm{C}(001) x \mathrm{M} / \mathrm{NiFe}$ photoanodes exhibited a significantly reduced reflectance compared to their planar counterparts due to light trapping effect at the surface of the nanoporous structure. Planar $3 \mathrm{C}(111) / \mathrm{NiFe}$ and $3 \mathrm{C}(001) / \mathrm{NiFe}$ showed a high reflectance of over $20 \%$ at wavelengths less than $500 \mathrm{~nm}$. With increasing the anodization time from 1 to $10 \mathrm{~min}$, the resulting nanoporous photoanodes showed a gradual decrease of the reflectance, consistent with the increase of the surface area (Tables 1 and 2). With the anodization time $\geq 5 \mathrm{~min}$, the nanoporous photoanodes showed a reflectance less than $5 \%$ in the wavelength range of $<500 \mathrm{~nm}$, which resulted in a high LHE of over $95 \%$ (Tables 1 and 2). This result reveals that nanoporous 3C-SiC photoanodes significantly reduce light reflectance, thus increasing the light absorption due to trapping effect.

To quantitatively demonstrate the effect of the nanoporous $3 \mathrm{C}-\mathrm{SiC}$ structure on the improvement of charge-separation efficiency $\left(\Phi_{\text {sep }}\right)$ and charge-injection efficiency into electrolyte for water oxidation $\left(\Phi_{\mathrm{ox}}\right)$, we measured the $J-V$ curves of the photoanodes in $1 \mathrm{M} \mathrm{NaOH}$ with $5 \% \mathrm{H}_{2} \mathrm{O}_{2}$ (Figure $6 \mathrm{~B}$ ). $J_{\mathrm{ph}}$ can be defined as $J_{\mathrm{ph}}=J_{\mathrm{Abs}} \Phi_{\mathrm{sep}} \Phi_{\mathrm{ox}}{ }^{42}$ where $J_{\mathrm{Abs}}$ is the photocurrent density converted from all absorbed photons by the photoanode at a $100 \%$ quantum efficiency. By integrating the solar AM1.5G spectrum with LHE, we obtained $J_{\mathrm{Abs}}$ for both nanoporous $3 \mathrm{C}(111) x \mathrm{M} / \mathrm{NiFe}$ and $3 \mathrm{C}(001) x \mathrm{M} / \mathrm{NiFe}$ photoanodes, which is also increasing with the increase of the anodization time (Tables 1 and 2). The improved $J_{\text {Abs }}$ clearly evidence that the nanoporous structure enhances the light-harvesting efficiency. Since $\mathrm{H}_{2} \mathrm{O}_{2}$ is a hole scavenger enabling complete utilization of the photogenerated holes arrived at the electrode/electrolyte interface, namely, $\Phi_{\text {ox }}\left(\mathrm{H}_{2} \mathrm{O}_{2}\right)=100 \%$, the photocurrent density measured with $\mathrm{H}_{2} \mathrm{O}_{2}$ in the electrolyte is given by $\mathrm{J}_{\mathrm{H}_{2} \mathrm{O}_{2}}=$ $J_{\mathrm{Abs}} \Phi_{\text {sep. }}$. Therefore, we can get $\Phi_{\mathrm{ox}}=J_{\mathrm{ph}} / J_{\mathrm{H}_{2} \mathrm{O}_{2}}$ and $\Phi_{\text {sep }}=J_{\mathrm{H}_{2} \mathrm{O}_{2}} /$ $J_{\mathrm{Abs}}$.
Figure 6C shows the calculated $\Phi_{\text {ox }}$ as a function of the potential for the planar and nanoporous photoanodes. Both the planar $3 \mathrm{C}(111) / \mathrm{NiFe}$ and $3 \mathrm{C}(001) / \mathrm{NiFe}$ showed very similar $\Phi_{\text {ox, }}$ which is expected due to the identical coating (in terms of morphology and thickness) of $\mathrm{Ni}: \mathrm{FeOOH}$ cocatalyst. In contrast, the nanoporous $\mathrm{p} 3 \mathrm{C}(111) 5 \mathrm{M} / \mathrm{NiFe}$ demonstrated a much steeper increase of $\Phi_{\mathrm{ox}}$ than $\mathrm{p} 3 \mathrm{C}(001) 5 \mathrm{M} / \mathrm{NiFe}$ and reached a plateau of $\sim 70 \%$ at a very low potential of $\sim 0.2 \mathrm{~V}_{\mathrm{RHE}}$. This result is probably due to the presence of columnar pore structure in $3 \mathrm{C}(111)$ that facilitates the deposition of $\mathrm{Ni}: \mathrm{FeOOH}$ in pores, thus increasing the number of the active catalytic sites. This explanation is supported by the larger surface area of nanoporous $3 \mathrm{C}(111)$ than that of nanoporous $3 \mathrm{C}(001)$, as seen in Tables 1 and 2. Moreover, it should be noted that p3C(111) $5 \mathrm{M} / \mathrm{NiFe}$ exhibited the highest $\Phi_{\text {ox }}$ of $91 \%$ at 1.23 $\mathrm{V}_{\mathrm{RHE}}$, significantly outperforming its planar counterpart $\left(\Phi_{\mathrm{ox}}=\right.$ $53 \%$ at $1.23 \mathrm{~V}_{\mathrm{RHE}}$ for $\left.3 \mathrm{C}(111) / \mathrm{NiFe}\right)$. Here, the results clearly reveal that compared to planar photoanodes, the nanoporous photoanodes significantly improve the charge-injection efficiency for water oxidation due to their large surface area that increases the number of the active catalytic sites.

Figure $6 \mathrm{D}$ shows the calculated $\Phi_{\text {sep }}$ curves of the planar and nanoporous photoanodes. Both the planar and nanoporous $3 \mathrm{C}$ $\mathrm{SiC}(111)$ photoanodes showed higher charge-separation efficiency than the respective $3 \mathrm{C}-\mathrm{SiC}(001)$ photoanodes. This result agrees very well with EIS results that smaller $R_{\text {bulk }}$ was observed in both the planar and nanoporous $3 \mathrm{C}-\mathrm{SiC}(111)$ photoanodes than those in the $3 \mathrm{C}-\mathrm{SiC}(001)$ photoanodes (Table S3). A reason for these results may be that $3 \mathrm{C}-\mathrm{SiC}(111)$ exhibited higher crystalline quality and longer carrier lifetime than $3 \mathrm{C}-\mathrm{SiC}(001),{ }^{25,26}$ as discussed in EIS results above.

As for the nanoporous photoanodes, both p3C(111)5M/ $\mathrm{NiFe}$ and $\mathrm{p} 3 \mathrm{C}(001) 5 \mathrm{M} / \mathrm{NiFe}$ exhibited a significant enhancement of $\Phi_{\text {sep }}$ with respect to their planar counterparts (Figure $6 \mathrm{D}) \cdot \mathrm{p} 3 \mathrm{C}(111) 5 \mathrm{M} / \mathrm{NiFe}$ showed the highest $\Phi_{\text {sep }}$ of $38 \%$, and $\mathrm{p} 3 \mathrm{C}(001) 5 \mathrm{M} / \mathrm{NiFe}$ exhibited the $\Phi_{\text {sep }}$ of $28 \%$ at $1.23 \mathrm{~V}_{\mathrm{RHE}}$. Both are increased by a factor of $\sim 1.4$ compared to their planar counterparts $\left(\Phi_{\text {sep }}=28 \%\right.$ for $3 \mathrm{C}(111) / \mathrm{NiFe}$ and $\Phi_{\text {sep }}=19 \%$ for $3 \mathrm{C}(111) / \mathrm{NiFe}$ at $\left.1.23 \mathrm{~V}_{\mathrm{RHE}}\right)$. In this work, we clearly demonstrate that nanoporous structure in $3 \mathrm{C}-\mathrm{SiC}$ synergistically enhances light-harvesting efficiency, charge-separation efficiency, and charge-injection efficiency for water oxidation, thus evidently improving the overall PEC water splitting performance.

To further understand the improvements of nanoporous $3 \mathrm{C}$ $\mathrm{SiC}$ photoanodes in PEC water splitting, we measured the incident photon-to-current efficiencies (IPCEs) of the $3 \mathrm{C}(111) / \mathrm{NiFe}, \mathrm{p} 3 \mathrm{C}(111) 5 \mathrm{M} / \mathrm{NiFe}, 3 \mathrm{C}(001) / \mathrm{NiFe}$, and $\mathrm{p} 3 \mathrm{C}(001) 5 \mathrm{M} / \mathrm{NiFe}$ photoanodes (Figure S13). For both $3 \mathrm{C}(111)$ and $3 \mathrm{C}(001)$, the nanoporous photoanodes exhibit higher IPCE than their planar counterparts. Compared to the IPCE of $20.1 \%$ for the planar $3 \mathrm{C}(111) / \mathrm{NiFe}$, the nanoporous $\mathrm{p} 3 \mathrm{C}(111) 5 \mathrm{M} / \mathrm{NiFe}$ exhibited a higher IPCE of $28.3 \%$ at 410 $\mathrm{nm}$. The improved IPCEs of nanoporous photoanodes agree very well with the enhancement of the photocurrent, lightharvesting, charge-separation, and charge-injection efficiencies.

\section{CONCLUSION}

In summary, we have demonstrated a facile anodization method to fabricate nanoporous $3 \mathrm{C}$-SiC photoanodes coupled with $\mathrm{Ni}: \mathrm{FeOOH}$ cocatalyst that extraordinarily improve solar water splitting performance compared to their planar counterparts. The calculation results show that $3 \mathrm{C}-\mathrm{SiC}$ exhibits a small value 
of $\left(L_{\mathrm{D}}+W_{\text {dep }}\right)$ with respect to the large light penetration depth, which significantly limits the charge separation and results in a small photocurrent. We show that this drawback can be overcome by fabrication of nanoporous structure. The optimized nanoporous $3 \mathrm{C}$-SiC photoanode achieved a high photocurrent density of $2.30 \mathrm{~mA} \mathrm{~cm}^{-2}$ at $1.23 \mathrm{~V}_{\mathrm{RHE}}$ under 1 sun illumination, which is 3.3 times higher than that of its planar counterpart. To our knowledge, this PEC water splitting photocurrent is the highest value ever reported for $3 \mathrm{C}-\mathrm{SiC}$ as a photoanode under AM1.5G $100 \mathrm{~mW} \mathrm{~cm}^{-2}$ illumination. The quantitative studies evidence that the nanoporous structure dramatically reduces light reflection, enlarges the electrochemically active surface area, and improves the charge-separation and -injection efficiencies, thus significantly enhancing the PEC water oxidation performance. Moreover, we find that the nanoporous $3 \mathrm{C}-\mathrm{SiC}(111)$ shows a better PEC performance than the nanoporous $3 \mathrm{C}-\mathrm{SiC}(001)$ due to its higher crystalline quality (thus higher $\Phi_{\text {sep }}$ ) and larger surface area (thus higher $\left.\Phi_{\text {ox }}\right)$. This work proposes a strategy for tailoring $3 \mathrm{C}-\mathrm{SiC}$ for solar hydrogen production, which is also applicable for designing other indirect band gap semiconductors for solar energy conversion.

\section{METHODS}

Materials. High-quality thick $(\sim 1 \mathrm{~mm}) 3 \mathrm{C}-\mathrm{SiC}(111)$ films were epitaxially grown on $4^{\circ}$ off-axis $4 \mathrm{H}-\mathrm{SiC}(0001)$ substrates by sublimation epitaxy growth. ${ }^{26}$ Then, freestanding, $\sim 300 \mu \mathrm{m}$ thick $3 \mathrm{C}-\mathrm{SiC}(111)$ films were obtained by polishing away the substrate and the interfacial layer. The commercial 3C-SiC(001) wafer (Hoya Corp.) was initially grown on $\mathrm{Si}(001)$ substrate and $\sim 260 \mu \mathrm{m}$ thick freestanding $3 \mathrm{C}-\mathrm{SiC}(001)$ were obtained after removal of the substrate. Prior to the preparation of photoanodes, $3 \mathrm{C}-\mathrm{SiC}(111)$ and $3 \mathrm{C}$ $\mathrm{SiC}(001)$ were chemically cleaned with acetone, ethanol, $\mathrm{H}_{2} \mathrm{O}: \mathrm{H}_{2} \mathrm{O}_{2}: \mathrm{NH}_{3}(5: 1: 1)$, and $\mathrm{H}_{2} \mathrm{O}: \mathrm{H}_{2} \mathrm{O}_{2}: \mathrm{HCl}(6: 1: 1)$ as well as $\mathrm{HF}$ (5\%) solutions. Then, the $3 \mathrm{C}-\mathrm{SiC}$ photoanodes were fabricated by the deposition of $200 \mathrm{~nm}$ thick $\mathrm{Al}$ Ohmic contacts on the backside of 3C$\mathrm{SiC}$, followed by an epoxy resin sealing of backside and edges so that only the surface was exposed to the electrolyte.

Fabrication of Nanoporous 3C-SiC. The nanoporous 3C$\mathrm{SiC}(111)$ and $3 \mathrm{C}-\mathrm{SiC}(001)$ photoanodes were fabricated by an anodization method in a two-electrode cell under the same conditions. The planar 3C-SiC photoanode was connected to a $1 \times 1 \mathrm{~cm}^{2} \mathrm{Pt}$ cathode at $6 \mathrm{~V}$ (versus $\mathrm{Pt}$ ) in a 5\% HF solution under $410 \mathrm{~nm}$ LED illumination $\left(\sim 50 \mathrm{~mW} \mathrm{~cm}^{-2}\right)$. The nanoporous structure and depth in $3 \mathrm{C}-\mathrm{SiC}(111)$ and $3 \mathrm{C}-\mathrm{SiC}(001)$ were controlled by varying the anodization time from 1, 2, 5 to $10 \mathrm{~min}$, respectively.

Preparation of Ni:FeOOH Cocatalyst. Prior to PEC water splitting measurements, a $\mathrm{Ni}$ :FeOOH layer was deposited on $3 \mathrm{C}-\mathrm{SiC}$ as the OER cocatalyst and the protection layer. For one-step deposition of $\mathrm{Ni}: \mathrm{FeOOH}$, a $25 \mathrm{~mL}$ precursor solution was prepared with $1 \mathrm{mM} \mathrm{FeCl}_{3}$ and $0.1 \mathrm{M} \mathrm{NiCl}_{2}$, considering that the solubility product constant of $\mathrm{Ni}(\mathrm{OH})_{2}\left(K_{\mathrm{sp}}=5.48 \times 10^{-16}\right)$ is much larger than that of FeOOH $\left(K_{\mathrm{sp}}\right.$ $\left.=2.79 \times 10^{-35}\right)$. In addition, $25 \mathrm{~mL}$ of urea $(45 \mathrm{mM})$ was added to serve as the progressive $\mathrm{OH}^{-}$releasing agent. Then, the $3 \mathrm{C}-\mathrm{SiC}$ photoanodes were immersed in the solution, which was heated to $100{ }^{\circ} \mathrm{C}$ to evaporate half of the solution. Finally, the $\mathrm{Ni} F \mathrm{FeOOH}$-coated photoanodes were rinsed with deionized water and air-dried.

Characterizations. The XRD measurements were performed using a Philips MRD with $\mathrm{Cu} \mathrm{K} \alpha_{1}(\lambda=1.54 \AA)$. SEM and EDXS were measured by a LEO $1550 \mathrm{Gemini}$ instrument. PEC measurements were carried out in a three-electrode cell by a potentiostat (Princeton Applied Research, VersaSTAT 3) in 1.0 M NaOH solution ( $\mathrm{pH}=13.6)$ under AM1.5G $100 \mathrm{~mW} \mathrm{~cm}^{-2}$ illumination from solar simulator (LOTQuantum Design $\mathrm{GmbH}$, calibrated by a standard Si photovoltaic cell). Prior to PEC measurements, the solution was deoxygenated by bubbling with high-purity (99.999\%) Ar gas for over $30 \mathrm{~min}$. The prepared $3 \mathrm{C}$-SiC photoanode, $1 \times 1 \mathrm{~cm}^{2}$ Pt plate, and $\mathrm{Ag} / \mathrm{AgCl}$ (saturated $\mathrm{KCl}$ ) were used as the working electrode, the counter electrode, and the reference electrode, respectively. The current density-potential measurements were performed at a scan rate of 30 $\mathrm{mV} \mathrm{s}^{-1}$. The potential measured with respect to $\mathrm{Ag} / \mathrm{AgCl}\left(V_{\mathrm{Ag} / \mathrm{AgCl}}\right)$ was converted to the potential versus reversible hydrogen electrode $\left(V_{\mathrm{RHE}}\right)$ using the following equation: $V_{\mathrm{RHE}}=V_{\mathrm{Ag} / \mathrm{AgCl}}+E_{0}+0.059 \mathrm{pH}$, where $E_{0}$ is the potential of the $\mathrm{Ag} / \mathrm{AgCl}$ reference electrode with respect to the standard hydrogen potential. The amounts of the evolved $\mathrm{O}_{2}$ and $\mathrm{H}_{2}$ gases were measured using a gas chromatograph (Agilent Technologies MicroGC490). The Faradaic efficiency was calculated by the ratio of the detected gas to the expected amount from photocurrent assuming $100 \%$ Faradaic efficiency.

\section{ASSOCIATED CONTENT}

\section{Supporting Information}

The Supporting Information is available free of charge at https://pubs.acs.org/doi/10.1021/acsnano.1c00256.

Additional details on SEM images, elemental mapping, EDXS, XRD patterns, chopped $J-V$ curves, cyclic voltammetry curves, reflectance spectra, transmittance spectra, light-harvesting efficiencies, and IPCE of the planar and nanoporous photoanodes; table showing a comparison of the photocurrent densities and ABPE of the reported $3 \mathrm{C}-\mathrm{SiC}$ photoanodes (PDF)

\section{AUTHOR INFORMATION}

\section{Corresponding Author}

Jianwu Sun - Department of Physics, Chemistry and Biology (IFM), Linköping University, SE-58183 Linköping, Sweden; 이이.org/0000-0002-6403-3720; Email: jianwu.sun@ liu.se

\section{Authors}

Jing-Xin Jian - Department of Physics, Chemistry and Biology (IFM), Linköping University, SE-58183 Linköping, Sweden

Valdas Jokubavicius - Department of Physics, Chemistry and Biology (IFM), Linköping University, SE-58183 Linköping, Sweden

Mikael Syväjärvi - Department of Physics, Chemistry and Biology (IFM), Linköping University, SE-58183 Linköping, Sweden

Rositsa Yakimova - Department of Physics, Chemistry and Biology (IFM), Linköping University, SE-58183 Linköping, Sweden

Complete contact information is available at:

https://pubs.acs.org/10.1021/acsnano.1c00256

\section{Notes}

The authors declare no competing financial interest.

\section{ACKNOWLEDGMENTS}

This work is supported by The Swedish Research Council (Vetenskapsrådet, Grant No. 2018-04670 and Grant No. 202004400), The Swedish Research Council for Environment, Agricultural Sciences and Spatial Planning (FORMAS, Grant No. 2016-00559), The Swedish Foundation for International Cooperation in Research and Higher Education (STINT, Grant No. CH2016-6722), and The ÅForsk foundation (Grant No. 19-311).

\section{REFERENCES}

(1) Fujishima, A.; Honda, K. Electrochemical Photolysis of Water at a Semiconductor Electrode. Nature 1972, 238, 37-38. 
(2) Nocera, D. G. The Artificial Leaf. Acc. Chem. Res. 2012, 45, 767776.

(3) Yang, J. H.; Wang, D. E.; Han, H. X.; Li, C. Roles of Cocatalysts in Photocatalysis and Photoelectrocatalysis. Acc. Chem. Res. 2013, 46, 1900-1909.

(4) Joya, K. S.; Joya, Y. F.; Ocakoglu, K.; van de Krol, R. WaterSplitting Catalysis and Solar Fuel Devices: Artificial Leaves on the Move. Angew. Chem., Int. Ed. 2013, 52, 10426-10437.

(5) Sambur, J. B.; Chen, T. Y.; Choudhary, E.; Chen, G.; Nissen, E. J.; Thomas, E. M.; Zou, N.; Chen, P. Sub-Particle Reaction and Photocurrent Mapping to Optimize Catalyst-Modified Photoanodes. Nature 2016, 530, 77-80.

(6) Montoya, J. H.; Seitz, L. C.; Chakthranont, P.; Vojvodic, A.; Jaramillo, T. F.; Norskov, J. K. Materials for Solar Fuels and Chemicals. Nat. Mater. 2017, 16, 70-81.

(7) Yu, Y. H.; Zhang, Z.; Yin, X.; Kvit, A.; Liao, Q. L.; Kang, Z.; Yan, X. Q.; Zhang, Y.; Wang, X. D. Enhanced Photoelectrochemical Efficiency and Stability Using a Conformal $\mathrm{TiO}_{2}$ Film on a Black Silicon Photoanode. Nat. Energy 2017, 2, 17045.

(8) Wu, H. L.; Li, X. B.; Tung, C. H.; Wu, L. Z. Recent Advances in Sensitized Photocathodes: From Molecular Dyes to Semiconducting Quantum Dots. Adv. Sci. 2018, 5, 1700684.

(9) Sokol, K. P.; Robinson, W. E.; Warnan, J.; Kornienko, N.; Nowaczyk, M. M.; Ruff, A.; Zhang, J. Z.; Reisner, E. Bias-Free Photoelectrochemical Water Splitting with Photosystem II on a DyeSensitized Photoanode Wired to Hydrogenase. Nat. Energy 2018, 3, 944-951.

(10) Chen, Z. B.; Dinh, H. N.; Miller, E. Photoelectrochemical Water Splitting: Standards, Experimental Methods, and Protocols. Springer: New York, 2013.

(11) Pinaud, B. A.; Benck, J. D.; Seitz, L. C.; Forman, A. J.; Chen, Z. B.; Deutsch, T. G.; James, B. D.; Baum, K. N.; Baum, G. N.; Ardo, S.; Wang, H. L.; Miller, E.; Jaramillo, T. F. Technical and Economic Feasibility of Centralized Facilities for Solar Hydrogen Production via Photocatalysis and Photoelectrochemistry. Energy Environ. Sci. 2013, 6, 1983-2002.

(12) van de Krol, R., Grätzel, M., Eds. Photoelectrochemical Hydrogen Production; Springer: New York, 2012; DOI: 10.1007/978-1-46141380-6.

(13) Gratzel, M. Photoelectrochemical Cells. Nature 2001, 414, 338344.

(14) Hernandez-Alonso, M. D.; Fresno, F.; Suarez, S.; Coronado, J. M. Development of Alternative Photocatalysts to $\mathrm{TiO}_{2}$ : Challenges and Opportunities. Energy Environ. Sci. 2009, 2, 1231-1257.

(15) Kibria, M. G.; Nguyen, H. P. T.; Cui, K.; Zhao, S. R.; Liu, D. P.; Guo, H.; Trudeau, M. L.; Paradis, S.; Hakima, A. R.; Mi, Z. T. One-Step Overall Water Splitting under Visible Light Using Multiband InGaN/ GaN Nanowire Heterostructures. ACS Nano 2013, 7, 7886-7893.

(16) Guo, C. X.; Dong, Y. Q.; Yang, H. B.; Li, C. M. Graphene Quantum Dots as a Green Sensitizer to Functionalize ZnO Nanowire Arrays on F-Doped SnO2 Glass for Enhanced Photoelectrochemical Water Splitting. Adv. Energy Mater. 2013, 3, 997-1003.

(17) Luo, J. S.; Li, Z.; Nishiwaki, S.; Schreier, M.; Mayer, M. T.; Cendula, P.; Lee, Y. H.; Fu, K. W.; Cao, A. Y.; Nazeeruddin, M. K.; Romanyuk, Y. E.; Buecheler, S.; Tilley, S. D.; Wong, L. H.; Tiwari, A. N.; Gratzel, M. Targeting Ideal Dual-Absorber Tandem Water Splitting Using Perovskite Photovoltaics and $\mathrm{CuIn}_{\mathrm{x}} \mathrm{Ga}_{1-\mathrm{x}} \mathrm{Se}_{2}$ Photocathodes. Adv. Energy Mater. 2015, 5, 1501520.

(18) Kim, T. W.; Choi, K. S. Nanoporous $\mathrm{BiVO}_{4}$ Photoanodes with Dual-Layer Oxygen Evolution Catalysts for Solar Water Splitting. Science 2014, 343, 990-994.

(19) Murphy, A. B.; Barnes, P. R. F.; Randeniya, L. K.; Plumb, I. C.; Grey, I. E.; Horne, M. D.; Glasscock, J. A. Efficiency of Solar Water Splitting Using Semiconductor Electrodes. Int. J. Hydrogen Energy 2006, 31, 1999-2017.

(20) Yasuda, T.; Kato, M.; Ichimura, M.; Hatayama, T. SiC Photoelectrodes for a Self-Driven Water-Splitting Cell. Appl. Phys. Lett. 2012, 101, 053902.

(21) Song, J. T.; Mashiko, H.; Kamiya, M.; Nakamine, Y.; Ohtomo, A.; Iwasaki, T.; Hatano, M. Improved Visible Light Driven Photo- electrochemical Properties of 3C-SiC Semiconductor with Pt Nanoparticles for Hydrogen Generation. Appl. Phys. Lett. 2013, 103, 213901.

(22) Jian, J. X.; Sun, J. W. A Review of Recent Progress on Silicon Carbide for Photoelectrochemical Water Splitting. Solar RRL 2020, 4, 2000111.

(23) Ichikawa, N.; Kato, M.; Ichimura, M. The Enhanced Performance of 3C-SiC Photocathodes for the Generation of Hydrogen through the Use of Cocatalysts. Appl. Phys. Lett. 2016, 109, 153904.

(24) Ichikawa, N.; Ichimura, M.; Kato, M. Improved Performance of 3C-SiC Photocathodes by Using a pn Junction. Int. J. Hydrogen Energy 2017, 42, 22698-22703.

(25) Sun, J. W.; Ivanov, I. G.; Liljedahl, R.; Yakimova, R.; Syväjärvi, M. Considerably Long Carrier Lifetimes in High-Quality 3C-SiC (111). Appl. Phys. Lett. 2012, 100, 252101.

(26) Jokubavicius, V.; Yazdi, G. R.; Liljedahl, R.; Ivanov, I. G.; Yakimova, R.; Syvajarvi, M. Lateral Enlargement Growth Mechanism of 3C-SiC on Off-Oriented 4H-SiC Substrates. Cryst. Growth Des. 2014, 14, 6514-6520.

(27) Jokubavicius, V.; Yazdi, G. R.; Liljedahl, R.; Ivanov, I. G.; Sun, J. W.; Liu, X. Y.; Schuh, P.; Wilhelm, M.; Wellmann, P.; Yakimova, R.; Syvajarvi, M. Single Domain 3C-SiC Growth on Off-Oriented 4H-SiC Substrates. Cryst. Growth Des. 2015, 15, 2940-2947.

(28) Jian, J. X.; Shi, Y. C.; Ekeroth, S.; Keraudy, J.; Syvajarvi, M.; Yakimova, R.; Helmersson, U.; Sun, J. W. A Nanostructured NiO/cubic $\mathrm{SiC} p-n$ Heterojunction Photoanode for Enhanced Solar Water Splitting. J. Mater. Chem. A 2019, 7, 4721-4728.

(29) Jian, J. X.; Shi, Y. C.; Syväjärvi, M.; Yakimova, R.; Sun, J. W. Cubic $\mathrm{SiC}$ Photoanode Coupling with $\mathrm{Ni}: \mathrm{FeOOH}$ Oxygen-Evolution Cocatalyst for Sustainable Photoelectrochemical Water Oxidation. Solar RRL 2020, 4, 1900364.

(30) Li, H.; Shi, Y. C.; Shang, H.; Wang, W. M.; Lu, J.; Zakharov, A. A.; Hultman, L.; Uhrberg, R. I. G.; Syväjärvi, M.; Yakimova, R.; Zhang, L. Z.; Sun, J. W. Atomic-Scale Tuning of Graphene/Cubic SiC Schottky Junction for Stable Low-Bias Photoelectrochemical Solar-to-Fuel Conversion. ACS Nano 2020, 14, 4905-4915.

(31) Goldberg, Y., Levinshtein, M. E., Rumyantsev, S. L., Eds. Properties of Advanced Semiconductor Materials: GaN, AlN, InN, BN, SiC, SiGe; John Wiley \& Sons: New York, 2001.

(32) Patrick, L.; Choyke, W. Optical Absorption in $n$-Type Cubic SiC. Phys. Rev. 1969, 186, 775-777.

(33) Solangi, A.; Chaudhry, M. I. Absorption Coefficient of $\beta$-SiC Grown by Chemical Vapor Deposition. J. Mater. Res. 1992, 7, 539-541.

(34) Yamanaka, M.; Daimon, H.; Sakuma, E.; Misawa, S.; Yoshida, S. Temperature Dependence of Electrical Properties of $n$ - and $p$-Type 3CSiC. J. Appl. Phys. 1987, 61, 599-603.

(35) Chen, Y. Q.; Zhang, X. N.; Zhao, Q.; He, L.; Huang, C. K.; Xie, Z. P. $p$-Type 3C-SiC Nanowires and Their Optical and Electrical Transport Properties. Chem. Commun. 2011, 47, 6398-6400.

(36) Grivickas, V.; Manolis, G.; Gulbinas, K.; Jarašiūnas, K.; Kato, M. Excess Carrier Recombination Lifetime of Bulk $n$-Type 3C-SiC. Appl. Phys. Lett. 2009, 95, 242110.

(37) Cai, L. L.; Zhao, J. H.; Li, H.; Park, J.; Cho, I. S.; Han, H. S.; Zheng, X. L. One-Step Hydrothermal Deposition of Ni:FeOOH onto Photoanodes for Enhanced Water Oxidation. ACS Energy Lett. 2016, 1, 624-632.

(38) Li, B. Y.; Jian, J. X.; Chen, J. B.; Yu, X. L.; Sun, J. W. Nanoporous $6 \mathrm{H}-\mathrm{SiC}$ Photoanodes with a Conformal Coating of $\mathrm{Ni}-\mathrm{FeOOH}$ Nanorods for Zero-Onset-Potential Water Splitting. ACS Appl. Mater. Interfaces 2020, 12, 7038-7046.

(39) Chowdhury, M.; Ntiribinyange, M.; Nyamayaro, K.; Fester, V. Photocatalytic Activities of Ultra-Small $\beta$-FeOOH and $\mathrm{TiO}_{2}$ Heterojunction Structure under Simulated Solar Irradiation. Mater. Res. Bull. 2015, 68, 133-141.

(40) Cabán-Acevedo, M.; Stone, M. L.; Schmidt, J. R.; Thomas, J. G.; Ding, Q.; Chang, H.-C.; Tsai, M.-L.; He, J.-H.; Jin, S. Efficient Hydrogen Evolution Catalysis Using Ternary Pyrite-Type Cobalt Phosphosulphide. Nat. Mater. 2015, 14, 1245-1253.

(41) Klahr, B.; Gimenez, S.; Fabregat-Santiago, F.; Bisquert, J.; Hamann, T. W. Photoelectrochemical and Impedance Spectroscopic 
Investigation of Water Oxidation with "Co-Pi"-Coated Hematite

Electrodes. J. Am. Chem. Soc. 2012, 134, 16693-16700.

(42) Dotan, H.; Sivula, K.; Gratzel, M.; Rothschild, A.; Warren, S. C.

Probing the Photoelectrochemical Properties of Hematite $\left(\alpha-\mathrm{Fe}_{2} \mathrm{O}_{3}\right)$

Electrodes Using Hydrogen Peroxide as a Hole Scavenger. Energy

Environ. Sci. 2011, 4, 958-964. 